\title{
Review
}

\section{Kinase Signalling in Huntington's Disease}

\author{
Kathryn R. Bowles* and Lesley Jones \\ MRC centre for Neuropsychiatric Genetics and Genomics, School of Medicine, Cardiff University, Cardiff, UK
}

\begin{abstract}
Alterations in numerous signal transduction pathways and aberrant activity of specific kinases have been identified in multiple cell and mouse models of Huntington's disease (HD), as well as in human HD brain. The balance and integration of a network of kinase signalling pathways is paramount for the regulation of a wide range of cellular and physiological processes, such as proliferation, differentiation, inflammation, neuronal plasticity and apoptosis. Unbalanced activity within these pathways provides a potential mechanism for many of the pathological phenotypes associated with HD, such as transcriptional dysregulation, inflammation and ultimately neurodegeneration. The characterisation of aberrant kinase signalling regulation in $\mathrm{HD}$ has been inconsistent and may be a result of failure to consider integration between multiple signalling pathways, as well as alterations that may occur over time with both age and disease progression. Collating the information about the effect of mHTT on signalling pathways demonstrates that it has wide ranging effects on multiple pro- and anti-apoptotic kinases, resulting in the dysregulation of numerous complex interactions within a dynamic network.
\end{abstract}

Keywords: Huntington's disease, kinase signalling, inflammation, pro-survival, pro-apoptotic, AKT, MEK/ERK, CDK5/P35, MAPKs, P53, IKK

\section{INTRODUCTION}

Huntington's disease (HD) is an autosomal dominant monogenic neurodegenerative disorder caused by an expanded CAG repeat in the huntingtin (HTT) gene, resulting in a mutant HTT (mHTT) protein carrying an expanded polyglutamine (polyQ) repeat on exon1. HD is characterised primarily by motor disturbances, but is commonly accompanied by cognitive impairments and psychiatric abnormalities [1-5]. Progressive striatal neurodegeneration is a hallmark of HD that can be identified prior to motor symptom onset, however there is evidence for widespread neuropathology in HD brain, including degeneration of cortical and subcortical structures [4, 6-8]. mHTT neuronal intranuclear inclusions (NIIs) can be found throughout vulnerable neuronal populations in HD brain $[9,10]$, however whether these may play a protective or damaging role within the cell remains to be elucidated $[11,12]$.

\footnotetext{
${ }^{*}$ Correspondence to: Dr. Kathryn R. Bowles, MRC Centre for Neuropsychiatric Genetics and Genomics, 2nd Floor Hadyn Ellis Building, Maindy Road, Cathays, CF24 4HQ Cardiff, UK. Tel./Fax: +44 2920688470; E-mail: BowlesK@ cardiff.ac.uk.
}

Protein kinases have the ability to phosphorylate other proteins in order to regulate their function. and are responsible for the mediation of signal transduction as well as regulating multiple downstream effects $[13,14]$. Numerous kinase signalling pathways are thought to contribute to HD pathophysiology. They are known to counter toxic metabolic changes induced by mHTT and help to maintain neuronal survival $[15$, 16]. Alterations in kinase signalling are also likely to have implications for the maintenance of the chronic neuroinflammation observed in HD [17-19], and the regulation of transcription, a central mechanism contributing to HD pathogenesis [20-25], either by direct regulation or through the phosphorylation of other proteins [26-36]. mHTT is able to alter signalling events both upstream and downstream of multiple pro-survival and pro-apoptotic pathways, and therefore predicting patterns of signal transduction and cell fate is challenging [37]. Furthermore, a single pathway can elicit multiple effects, and may have both pro-survival and pro-apoptotic functions, dependent on tissue and cell type, subcellular localisation, the intensity and duration of its activation, and the presence of additional signalling mediators [38]. To date, 
the characterisation of kinase signalling in models of HD has been inconsistent, which may be a result of variability in experimental design or technique and the consideration of individual pathways in isolation away from integrative signalling networks. The kinase signalling pathways most commonly investigated in HD are discussed in this review; a representation of how they interact to form a broader, more complex signalling network can be found in Fig. 1, and a schematic detailing the overlapping effects of mHTT on prosurvival and pro-apoptotic pathways can be found in Fig. 8.

\section{PRO-SURVIVAL PATHWAYS}

\section{MEK/ERK pathway}

The mitogen activated protein kinase kinase/ extracellular signal-related kinase (MEK/ERK) pathway is a strong mediator of anti-apoptotic and pro-survival signalling [39] and is part of the mitogen activated protein kinase (MAPK) signalling cascade (Fig. 2). RAS- guanosine diphosphate (GDP) is converted into its active form RAS- guanosine triphosphate (GTP) by activation of receptor tyrosine kinases. RAS-GTP then activates MAPK kinase kinase members of the RAF kinase family, which phosphorylates the dual specificity kinase MEK1/2 (a MAPK kinase), which in turn phosphorylates threonine and tyrosine residues in ERK1/2 (a MAPK) [32, 40]. Activated ERKs are present in the cytoplasm, where they may regulate the activity of additional kinases, receptors and signalling pathways, or may translocate to the nucleus in order to phosphorylate transcription factors [31, 32].

ERK signalling mediates neuroprotection following diverse neuronal insults, such as excitotoxicity, DNA damage and hypoxia [41, 42]. The phosphorylation of ERK activates neuroprotective factors [26, 33, 43] and inactivates pro-apoptotic mediators by phosphorylation [44] or by targeting for ubiquitin-mediated proteolysis [45]. Correct regulation of this pathway is also critical for neuronal development: [46-48] and for the regulation of gliogenesis in the developing cortex [49]. Inhibition of MEK1/2 and ERK has been found to block the induction of brain derived neurotrophic factor (BDNF)-regulated genes [50], thus implicating this pathway as an important regulator of BDNF-induced transcriptional regulation. MEK inhibition was found to abrogate the protective effect of BDNF stimulation in the StHdh ${ }^{Q 111}$ immortalised cell model of HD [16], and ERK signalling has been identified as an integra- tion point for BDNF and glutamate signalling [37]. The MEK/ERK pathway is therefore likely to act as a key downstream modulator of BDNF activity.

The MEK/ERK signalling pathway is typically considered to be neuroprotective; consistent with this idea is the observation of its downregulation in neurodegenerative conditions such as ischemia [51] and traumatic spinal cord injury [52]. However, the role of MEK and ERK signalling in neuronal protection may depend on cellular context, such as cell type, tissue, the trigger of cellular insult and interactions with other signalling pathways $[53,54]$. The activation of ERK has been demonstrated to be detrimental to neurons in models of Alzheimer's disease (AD) and Parkinson's disease (PD) [55, 56], therefore MEK/ERK pathway activation may be able to facilitate apoptosis in particular cellular contexts, and the duration of activation may influence whether neurons enter a pro-survival or pro-apoptotic program $[57,58]$.

\section{MEK \& ERK in models of HD}

As MEK and ERK activity plays a role in striatal transcriptional regulation and regulation of the BDNF-mediated cellular response [16, 33, 37, 50], these pathways have been investigated as potential neuroprotective modulators of HD pathology [26, 59]. Overexpression of constitutively active MEK and subsequently enhanced ERK activity has been correlated with the reduction of caspase- 3 activation in a PC12 model of HD [26], which is likely to be protective due to the predicted attenuation of caspaseregulated cleavage of mHTT into toxic fragments [60-62]. Reduced ERK phosphorylation due to mHTTassociated mechanisms has also been found to decrease ERK-dependent expression of glutamate transporters in Drosophila, increasing glutamate signalling and toxicity in neighbouring cells [63]. In addition, ERK has been implicated in synaptic plasticity and memory, which may be relevant to the deficits seen in HD transgenic mouse models [64-68].

Despite the evidence suggesting a significant neuroprotective effect of enhanced MEK/ERK activity in $\mathrm{HD}$, there is disagreement about whether there is enhanced basal activity within this pathway in models of HD, or whether there is a reduction in activity in this pathway as a consequence of mHTTinduced cellular disruption. Table 1 summarises the disparity in the characterisation of MEK and ERK phosphorylation between multiple models of HD. Whether this inconsistency results from differences between the expression of full length or truncated forms of mHTT remains unclear; full length HTT 


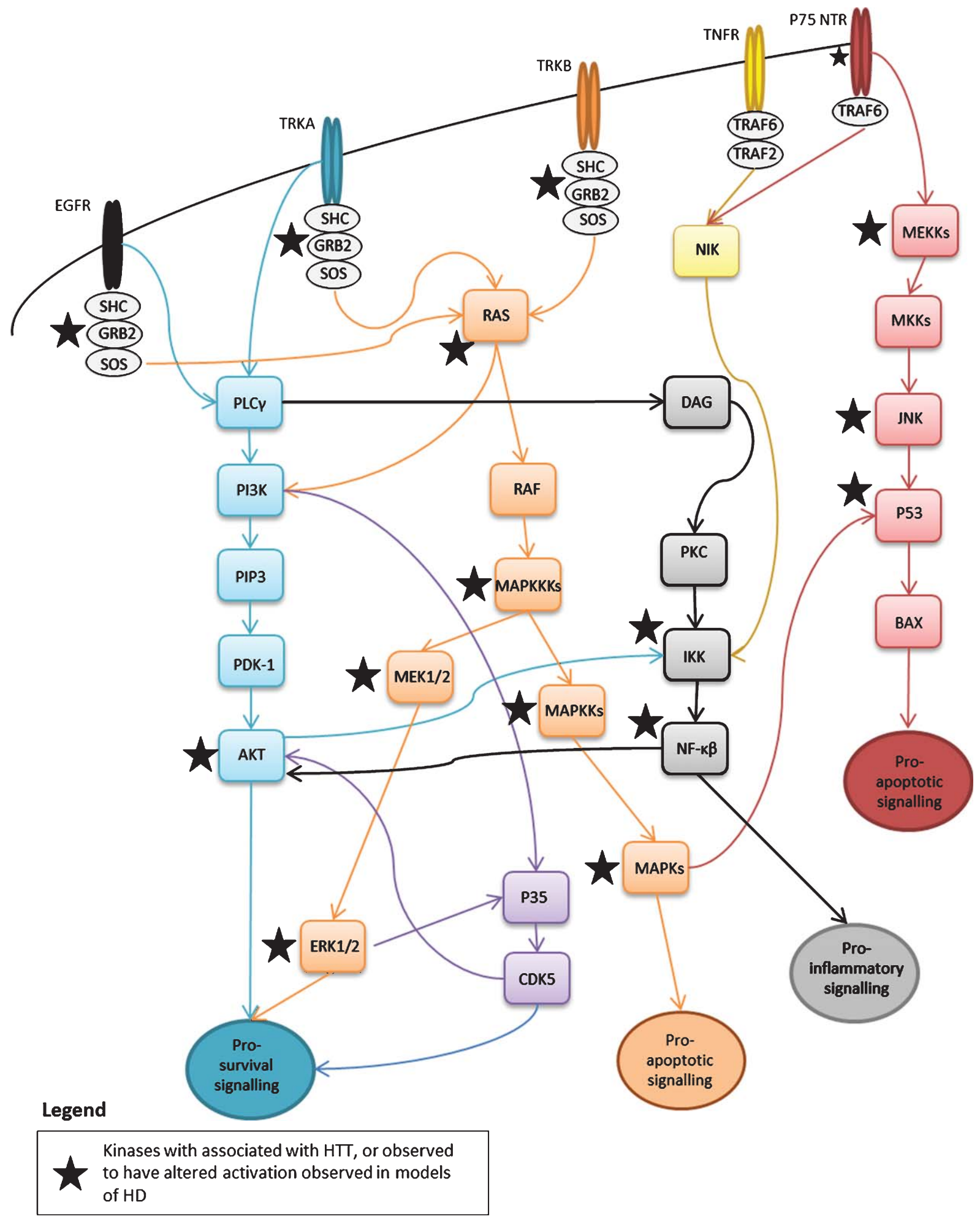

Fig. 1. A cartoon depicting the network of kinase signalling pathways downstream of growth factor receptor stimulation that have been most commonly investigated in HD. Black stars indicate points within these signalling cascades that have altered activation in models of HD, or have been found to associate with mHTT. 


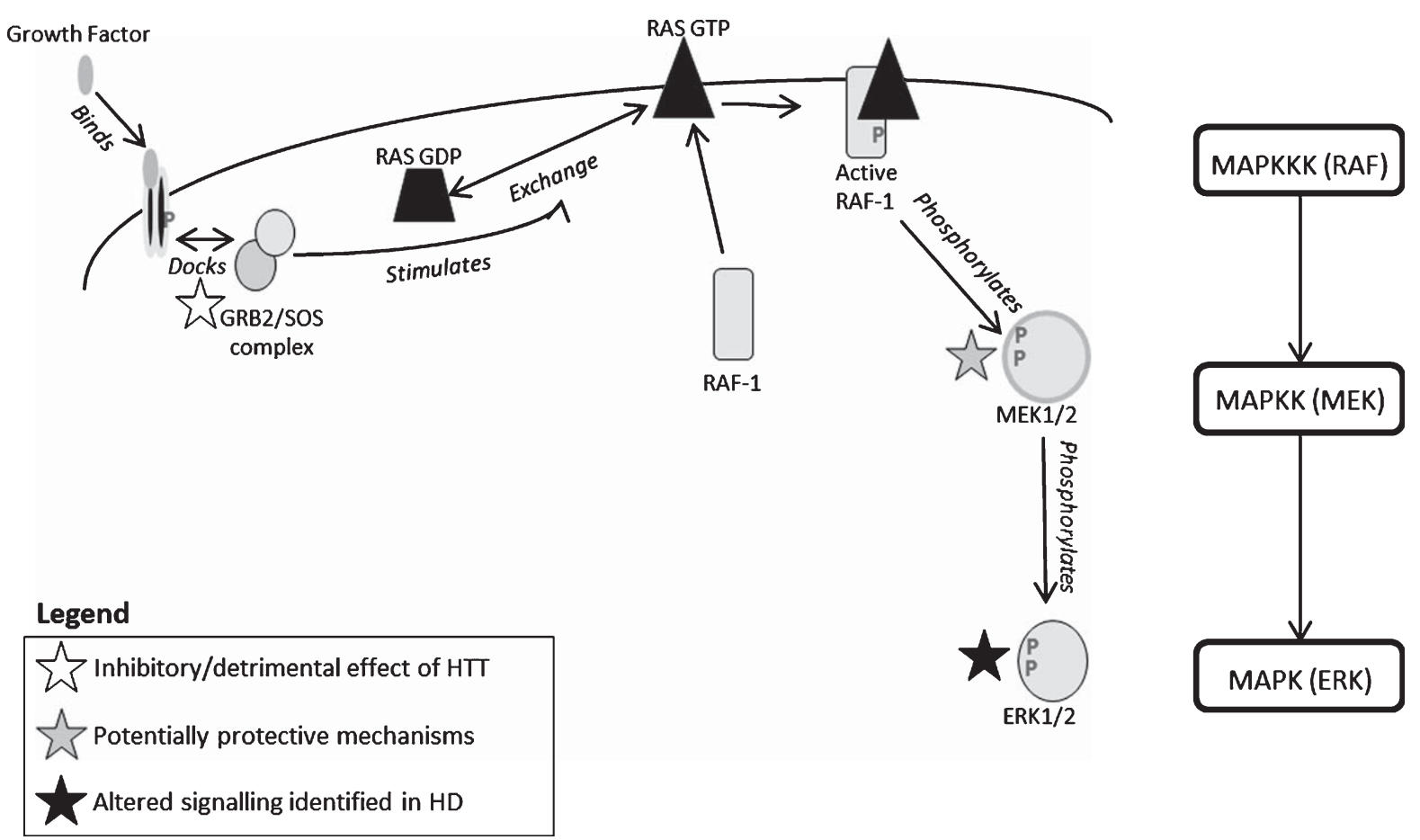

Fig. 2. Simplified cartoon of the MEK/ERK signalling pathway and flow diagram indicating its elements within the MAPK cascade. Stimulation of the phosphotyrosine kinase receptor initiates docking with the GRB2 adaptor protein/ SOS nucleotide exchange factor complex. The signal is transduced to stimulate the exchange of inactive RAS-GDP to active RAS-GTP. This prompts a conformational change in RAS, which recruits RAF-1 to the cell membrane, leading to its phosphorylation and activation. Active RAF-1 then phosphorylates and activates MEK1/2, which in turn phosphorylates and activates ERK1/2 (see [40] for a detailed review). Stars indicate points within the pathway that have been identified as being altered in models of HD, have been found to interact with $\mathrm{mHTT}$, or have alterations that may be protective. White stars represent inhibitory or detrimental effects of mHTT; blue/grey stars represent potentially protective mechanisms in HD; black stars mark where altered kinase signalling has been identified in HD, but the evidence for the nature of the effect has been mixed.

models tend to exhibit suppressed ERK activation [69, 70], although two truncated models, R6/1 and R6/2, show widespread variation in the activation status of ERK that is age, brain region and cell type dependent $[33,59,71-73]$. Drosophila carrying a truncated exon1 fragment also exhibit suppressed ERK phosphorylation [63], similar to the full-length HD models. The available transgenic mouse data suggests that an increase in ERK activity may be a progressive striatal phenotype: such progression would not be apparent in immortalised and embryonic cell cultures. This progression may not be exclusive to medium spiny neurons (MSNs); Fusco et al. (2012) suggest that in R6/2 MSNs, although ERK activation increases from 8-13 weeks of age, it remains either lower, or comparable, to the level of activation in wild type mice. However, in striatal cholinergic and somatostatinergic interneurons, although active ERK is reduced with age, it remains higher in these cells than in their wild type counterparts. As cholinergic and somatostatinergic interneurons are relatively spared in HD, enhanced ERK phosphorylation may be a mechanism for their improved survival. The reduction of ERK activity over time in R6/2 cortical neurons compared with the enhancement in striatal neurons [72] also suggests neuronal subtype specificity, as well as a potential mechanism for a loss of BDNF trophic support from cortical to striatal neurons typical of HD pathogenesis [74-76]. Apostol et al. (2006) suggest that as the expression of BDNF is a downstream target of ERK activity, reduced cortical ERK in HD models leads to increased cell death and suppressed BDNF expression. In turn, less trophic support is available to striatal neurons, which consequently mount a compensatory response including increased ERK activation.

MEK1 overexpression was found to be protective against cell death in PC12 cell models of HD [26], consistent with the anti-apoptotic effects of increasing downstream ERK activity (Figs. 1 and 2). However, MEK overexpression and increased ERK activation were found to have no protective effect on neuronal dysfunction or survival in Drosophila models of HD 


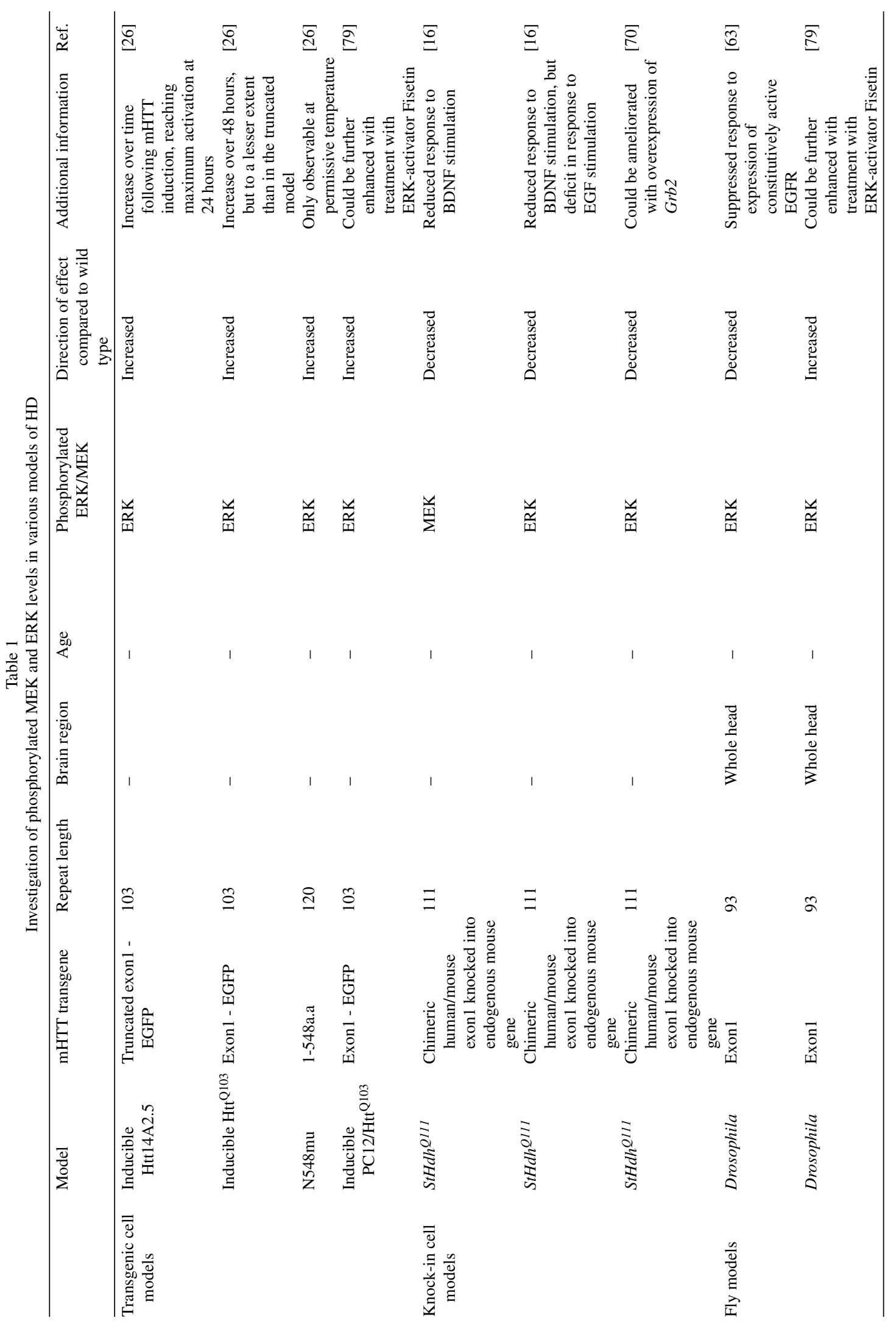




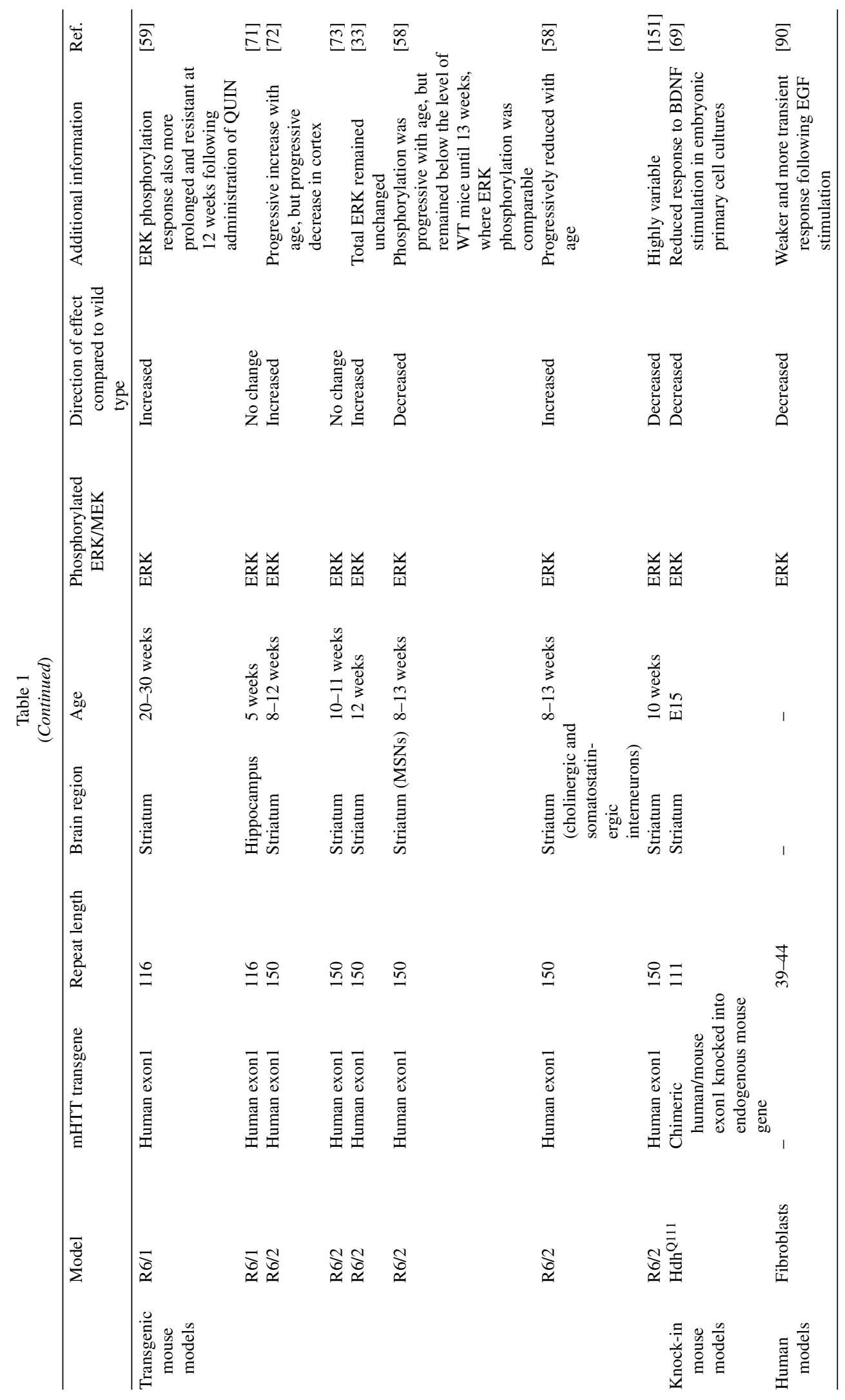




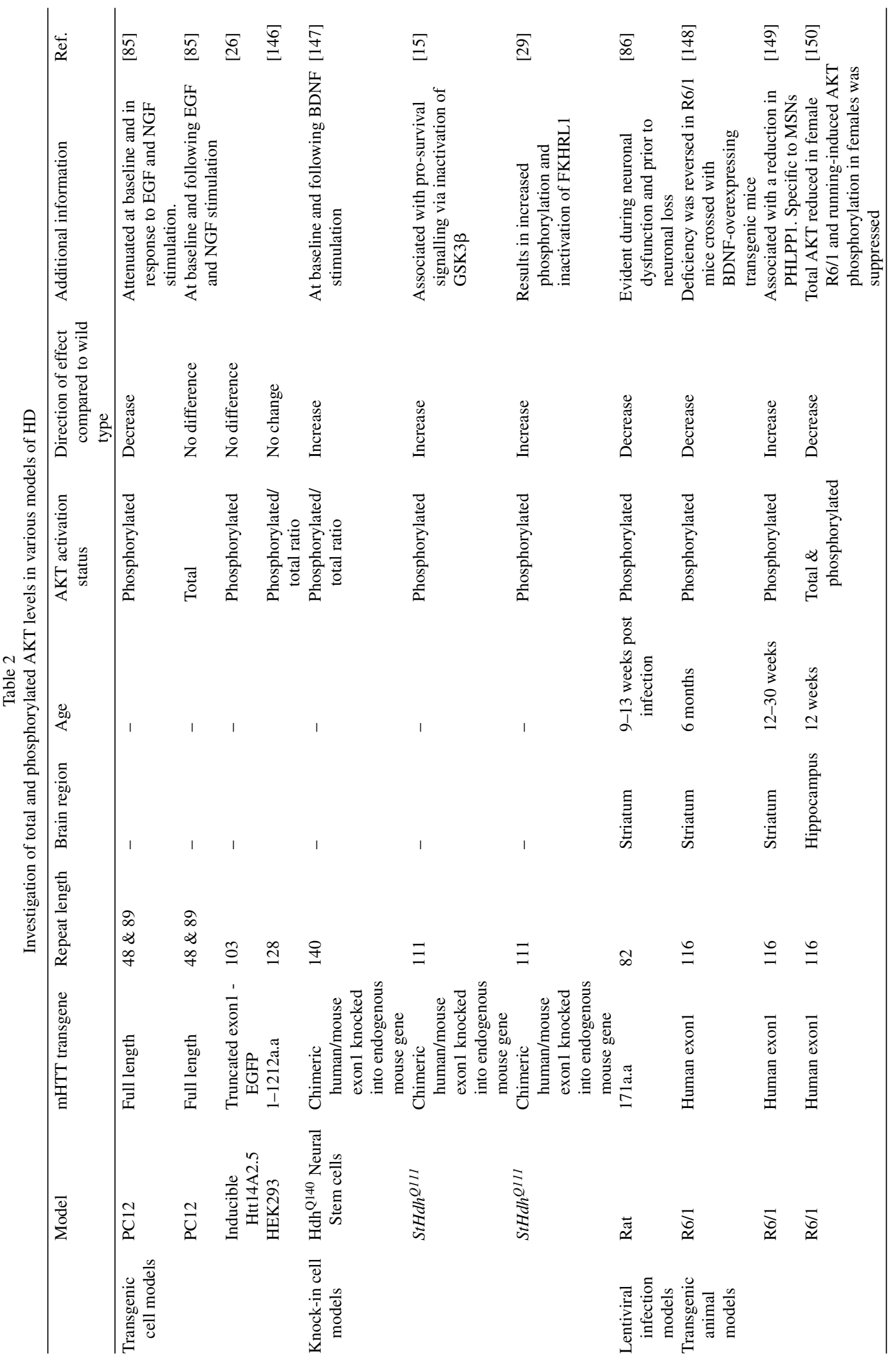




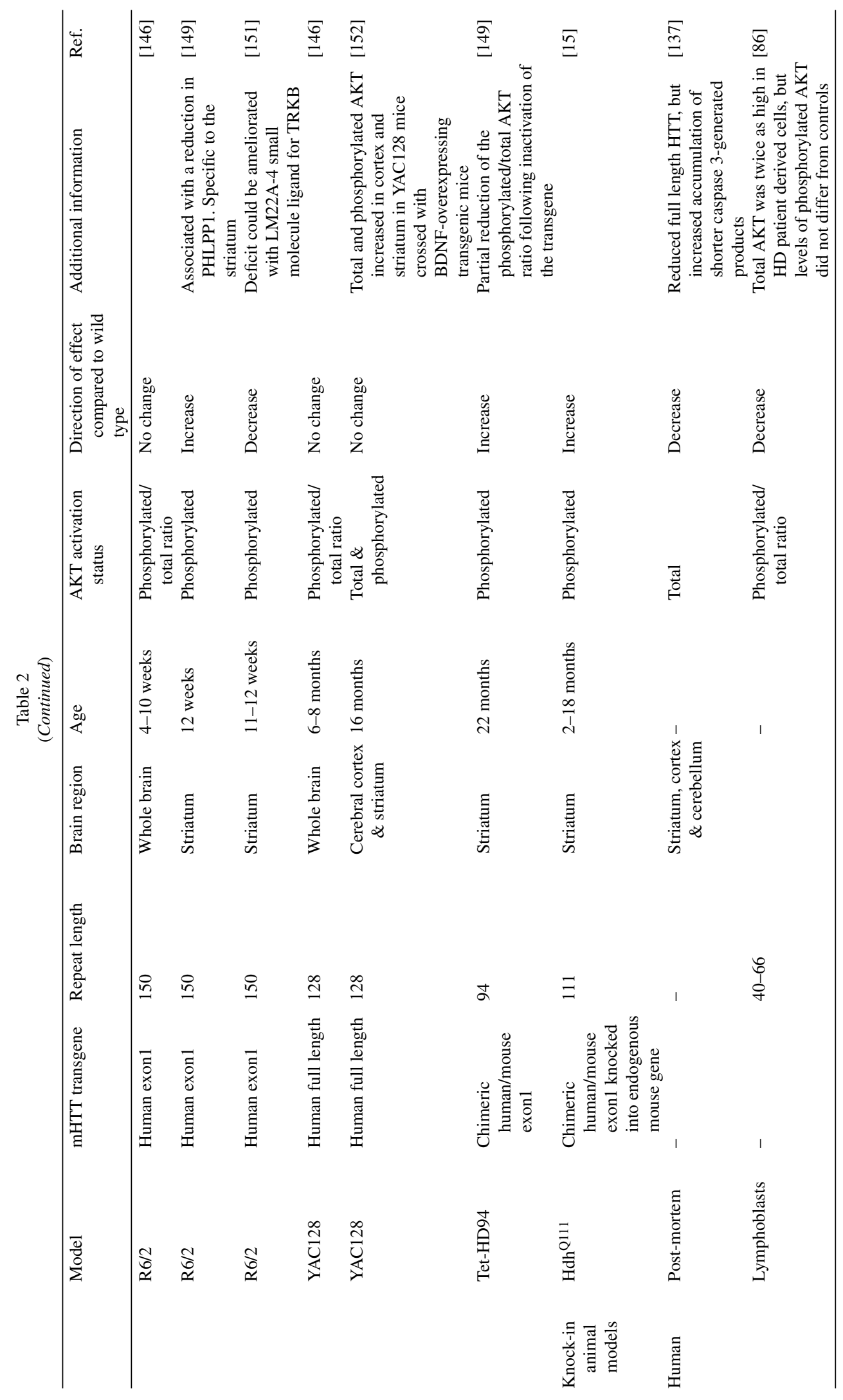




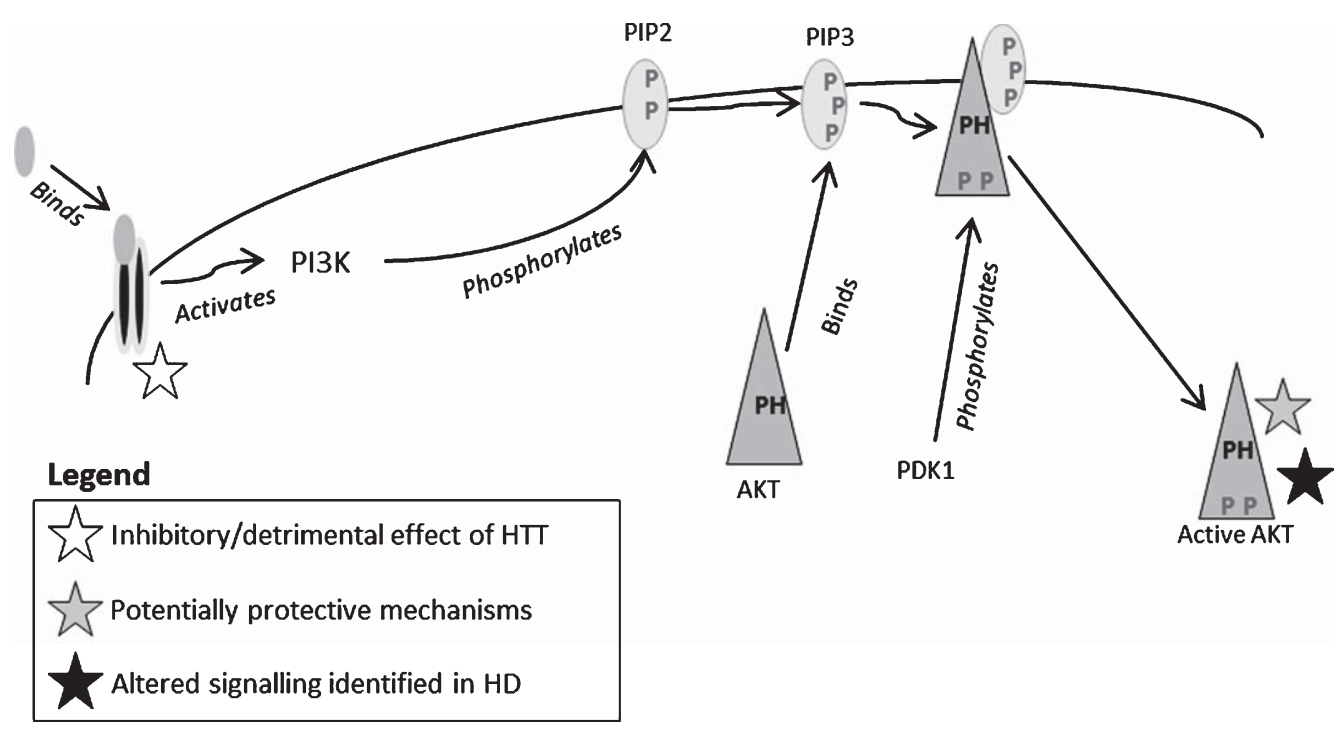

Fig. 3. Simplified cartoon depicting AKT activation. Growth factor binding to a receptor tyrosine kinase recruits PI3K to the plasma membrane where it is also activated. This initiates the phosphorylation of PIP2, creating PIP3. AKT is then anchored to PIP3 at the plasma membrane through its PH-domain This alters the conformation of AKT, therefore allowing its activation by phosphorylation of its tyrosine and serine residues by PDK1. (See [141] for a review). Stars indicate points within the pathway that have been identified as being altered in models of $\mathrm{HD}$, or have been found to interact with mHTT. White stars represent an inhibitory or detrimental effect of mHTT; blue/grey stars represent potentially protective mechanisms in HD; black stars mark where altered kinase signalling has been identified in HD, but the evidence for the nature of the effect has been mixed.

$[77,78]$. In contrast, in a more recent Drosophila model of HD, genetic reduction of the Drosophila Erk gene 'rolled' by $50 \%$ had no effect on fly survival or neurodegeneration; however reduction of the Mek gene 'dsor' significantly decreased survival [79]. Additionally, although ERK phosphorylation was found to be required for the neuroprotective effect of cannabinoid receptor agonists in a PC12 model of $\mathrm{HD}$, the number of additional surviving cells was less than $10 \%$, and not all cells exhibited the ERK phosphorylation response correlated with rescue [80]. These models suggest that ERK activation alone may not be sufficient for neuroprotection; targeting multiple signalling pathways may be required in order to form an effective neuroprotective response.

\section{Mechanisms for MEK/ERK alterations and neuronal protection}

Increased phosphorylation of ERK-activated transcription factors, such as ELK1 and CREB has been correlated with increased ERK phosphorylation in $\mathrm{R} 6 / 2$ striatum [33]. However, the expression of $C$-fos, an immediate-early gene associated with regulating neuronal survival [81], was downregulated in these mice [82]. It was suggested that attenuated expression of $C$-fos may be a result of mHTT-associated down- regulation of mitogen- and stress-activated kinase 1 (MSK1) activity [33], which is also a downstream target of ERK [83, 84]. Accordingly, the overexpression of MSK1 was able to restore $C$-fos transcription and was neuroprotective [33]. MSK1 expression is also decreased in human HD post-mortem caudate, but not in the cerebral cortex [33], therefore indicating tissue-specific effects of mHTT on the regulation of downstream targets of ERK.

MEK/ERK signalling is one of the multiple pathways downstream of epidermal growth factor receptor (EGFR) activation (Fig. 1), and the reductions in ERK phosphorylation that have been observed in several models of HD have been attributed to direct antagonism of the EGFR by mHTT [63, 85, 86] (Fig. 8). The EGFR complex interacts with both HTT and mHTT via the interaction of HTT proline rich motifs with SH3 domain-containing molecules $[26,78,85$, 87]. This association can be strengthened with EGF stimulation [87]. The EGFR complex includes growth factor receptor-bound protein 2 (GRB2), and aberrant association between mHTT and GRB2 can attenuate downstream signalling, including MEK/ERK and protein kinase B (AKT) phosphorylation [85, 87, 88]. Elevated expression of Grb2 has been observed in $S t H d h^{Q 111}$ cells, despite suppressed ERK 
phosphorylation [70]. It has been argued that GRB2 also plays a role in the autophagic removal of mHTT, and that aberrant interactions between the two occur on vesicular structures and eventually activate autophagy, independent of EGFR activation. Excess GRB2 in $S t H d h^{Q 111}$ cells may therefore be directed towards autophagic removal of mHTT rather than to the regulation of growth factor-stimulated signalling [70]. The redistribution of the EGFR to the late endosomal compartment is thought to be a prerequisite for EGF-dependent ERK signalling [89], and inhibition of this process by the expanded polyQ on mHTT has been proposed as a contributing factor in the suppression of ERK phosphorylation observed in human HD fibroblasts [90].

ERK phosphorylation can also be induced by BDNF stimulation [50, 69] (Fig. 1). As such, impairment of the BDNF-associated receptors P75 neurotrophin receptor (NTR) and tyrosine kinase $\mathrm{B}$ (TRKB) have been investigated as mechanisms for reduced ERK phosphorylation in several models of HD. Transfection of $S t H d h^{Q 111}$ cells with P75 NTR did not improve levels of BDNF-induced ERK phosphorylation [91], therefore reduced TRKB expression may be responsible for the attenuation of the BDNF-associated ERK response [91, 92] (Fig. 8). However, Ginés et al. (2010) found no alterations in TRKB phosphorylation in $S t H d h^{Q 111}$ cell lines, and suggested that diminished levels of P52/P46 SHC scaffolding proteins that couple the activated TRKB receptor to the RAS/MEK/ERK pathway (Figs. 1 and 2) may account for reduced ERK activation. Indeed, transfection of these cells with constitutively active RAS restored BDNF-associated ERK activation [16].

The accumulation of phosphorylated ERK and the pro-apoptotic kinase P38 MAPK in R6/1 striatum has been attributed to disruption of the brain-specific striatal-enriched protein tyrosine phosphatase (STEP) by phosphorylation [59] (Fig. 8). STEP activation has been associated with excitotoxic-induced cell death, and its activation can be enhanced by injection with the neurotoxin quinolinic acid (QUIN) [59]. In hippocampal cells, STEP inactivation leads to ERK phosphorylation and attenuated cell death [93], and in R6/1 striatum, increased STEP phosphorylation correlates with enhanced phosphorylation of ERK and P38 MAPK in 20-30 week old animals [59]. Furthermore, ERK phosphorylation was more prolonged and neurons were more resistant to cell death following a QUIN injection in 12 week old R6/1 striata, indicating that progressive STEP inactivation may be a neuroprotective mechanism that mediates neuronal responses to excitotoxicity through maintenance of the ERK pathway [59].

Increased MEK/ERK signalling may also confer neuroprotective effects in models of HD via direct interactions with the HTT protein that reduce expanded polyQ-associated toxicity. The presence of mHTT in a cell model of HD increased the expression of the lys-asp-glu-leu motif receptor (KDELR), which plays a role in endoplasmic reticular (ER) stress and activation of autophagy [94]. In this model, the autophagic removal of mHTT was enhanced by increased KDELR expression, but was prevented by inhibition of MEK [94]. The neuroprotective clearance of mHTT proteins in response to ER stress and KDELR expression may therefore occur via MEK/ERK pathway activation (Fig. 8). The phosphorylation of HTT is typically considered to be a neuroprotective mechanism by mediating its subcellular localisation [95-101], cleavage $[60,62,102]$ and interaction with other proteins [74, 103, 104]. MEK1 activation has been identified as a mechanism for enhancing HTT phosphorylation, whereas MEK inhibition reduced general HTT serine phosphorylation [105].

\section{CDK5/P35 signalling}

Cell division protein kinase 5 (CDK5) is a member of the serine/threonine CDK family, and is associated with a wide range of cellular functions including neural development, neuromuscular development and hippocampal neurogenesis (see [106] for a review). Expression of CDK5 is highest in neurons due to the specific neuronal expression of its activators P35 or P39 [107], which can be regulated by nerve growth factor (NGF) and BDNF stimulation via activation of the MEK/ERK and phosphatidylinositol4,5-bisphosphate 3-kinase (PI3K) signalling cascades [108-111]. It forms a negative feedback loop within the MEK/ERK pathway [111-113], inactivates c-jun $\mathrm{N}$-terminal kinase (JNK) [114] and activates the AKT signalling pathway [115] (Figs.1 and 8), implicating CDK5 in neuronal survival. CDK5 activity has been found to be crucial for neuronal survival during development and disease [116], although excessive CDK5 has been implicated in cell death induced by oxidative stress and neurotoxicity [116]. Calpain cleavage of $\mathrm{P} 35$ results in a truncated isoform, $\mathrm{P} 25$, which is associated with neurodegenerative diseases such as PD and AD [116]. This may be due to the mislocalisation of CDK5 by P25 activation [117], and the longer half-life of P25 leading to aberrantly prolonged CDK5 activation [118]. 


\section{CDK5/P35 in HD}

CDK5 activity is consistently found to suppress mHTT toxicity [119]. It interacts and co-localises with HTT in vitro and phosphorylates HTT on serine 434 [60]. Phosphorylation of this serine on mHTT reduces its caspase cleavage, diminishing the presence of toxic amino-terminal fragments, attenuating aggregate formation and preventing cell death [60]. CDK5 activity has been observed to be reduced in N171-82Q transgenic mouse brain, and consequently the neuroprotective phosphorylation of HTT on serine 434 was also suppressed in these mice [60]. As CDK5 was not present in any inclusion bodies, it was concluded that mHTT may be altering the interaction between CDK5 and its activator P35 [60].

The dysregulation of CDK5 occurs with aging and increased DNA damage. Acute DNA damage triggers enhanced CDK5 phosphorylation which results in the neuroprotective phosphorylation of HTT on serines 1181 and 1201 [119]. However, long term accumulation of DNA damage is associated with CDK5 downregulation [120]. Downregulation of CDK5 and $\mathrm{P} 35$ protein has been identified in post-mortem human HD brain [121, 122], however although total CDK5 is also suppressed in $S t H d h^{Q 111}$ cells and in 9 month Hdh ${ }^{\mathrm{Q} 11}$ mouse striata, the phosphorylated to total CDK ratio was substantially higher, suggesting enhanced activation within this pathway [122]. This was attributed to substantially higher P25 expression in these models [122] which may be pushing CDK5 activity towards a pro-apoptotic function rather than a neuroprotective one. Increased CDK5 activity also sensitised neuronal cells to stimulation with a dopamine receptor agonist, therefore enhancing vulnerability to excitotoxicity [122].

The neuroprotective potential of CDK5 is therefore likely to be dependent on factors such as age and disease progression, or any other cellular insult resulting in DNA damage. CDK5 could be initially high in models of HD, where it may act as either a compensatory protective mechanism by phosphorylating mHTT or as a pro-apoptotic mechanism by enhancing excitotoxic vulnerability, dependent on the ratio of P25 to P35 activators present. With the accumulation of mHTT toxicity and DNA damage over time, CDK5 may become suppressed, as observed in the N171-82Q mouse model of HD and in human brain. Reduced CDK5 activity stabilises microtubules, which are required for mHTT inclusion formation [123-126]. Microtubules are major targets of CDK5 [127]; CDK5 activation disrupts microtubule formation in primary cortical neuronal cultures, attenuating mHTT aggre- gation and toxicity [126]. Reduced CDK5 over time may therefore be a pathogenic mechanism contributing to mHTT inclusion formation. Due to the dependence of CDK5-associated neuroprotective mechanisms on multiple factors such as age and extent of DNA damage, this pathway should not be considered in isolation in models of HD (Fig. 8).

\section{AKT pathway}

The AKT signalling pathway is one of the most comprehensively characterised pathways in HD models, and its activation is universally considered to be anti-apoptotic and neuroprotective in both acute and chronic models of neurodegeneration [15, 128-132]. A primary mechanism of AKT-mediated neuroprotection is by its phosphorylation and inactivation of pro-apoptotic machinery, such as glycogen synthase kinase $3 \beta$ (GSK3 $\beta)$, BCL-2 associated death promoter (BAD), BIM, histone deacetylase 3 (HDAC3), I kappa $\beta$ kinase (IKK) forkhead family proteins and pro-caspase-9 [15, 28, 88, 133-139].

AKT levels are typically low in adult brain [128]; however its activation rises following stress and injury [140]. AKT activation generally occurs via the PI3K pathway following growth factor or cytokine signalling [134, 141] (Fig. 3). The active form can then translocate to cell nuclei and directly phosphorylate transcription factors [34], and inactivation of AKT occurs via the action of phosphatases [142, 143]. There are three highly homologous AKT isoforms; there is evidence that despite their similarities, the different AKTs may have some non-overlapping functions [144, 145], however AKT1 has been most thoroughly investigated in models of HD, and further references to 'AKT' in this review will refer to 'AKT1.'

\section{AKT in models of $H D$}

Activation of the AKT pathway has been determined in several cell and mouse models of HD [15, $26,29,85,86,146-152]$, as well as in human postmortem brain [137], a summary of which can be found in Table 2. Similar to MEK/ERK signalling, there are many inconsistencies in AKT regulation both between and within models. Enhanced AKT signalling has been attributed to the striatal-specific reduced expression of its inhibitor PHLPP1 in several mouse models of HD, which is also reduced in human putamen [149]. However, despite reduced expression of PHLPP1 in R6/2, R6/1 and HD94 striatum, AKT activation in transgenic models of HD is much more variable (Table 2). However, with the exception of 
one study [146], AKT phosphorylation has not been investigated longitudinally in transgenic mouse models, preventing the characterisation of any progressive phenotype. Early developmental-stage models and more slowly progressing knock-in models of HD tend to exhibit enhanced AKT activation, which may be an initial compensatory response that inhibits other pro-apoptotic stress-activated pathways such as JNK and P38 [141]. However, with disease progression, AKT activation becomes suppressed and less efficient, therefore no longer protecting against cell death. Suppression of AKT may be more prevalent in transgenic models due to the increased neurotoxicity of the truncated mutant fragment and accelerated progression of the motor and neuronal phenotype. This is consistent with suppressed AKT phosphorylation that is observed in human HD post-mortem brain [137]. This suppression was attributed to reduced full-length $60 \mathrm{kDa}$ AKT species in human post-mortem HD brain, and increased accumulation of a short $49 \mathrm{kDa}$ caspase- 3 generated product that may prevent AKT phosphorylation and activation [137].

Regardless of its activation in different models of HD, increasing AKT phosphorylation has consistently been found to be a protective mechanism. For example, activation of AKT in Drosophila alleviated mHTTinduced toxicity in the retina, although it did not prevent fly lethality [78], and expression of AKT in glia improved Drosophila locomotor activity [78]. AKT activation may directly alter the toxicity of mHTT by phosphorylation on serine $421[88,137]$. The phosphorylation of mHTT on serine 421 has been associated with reduced mHTT toxicity and accumulation of fragments, as well as the restoration of BDNF axonal transport in neurons [62, 78, 104, 153-155]. However, as AKT activation in amino-terminal models lacking this serine is still protective, it is likely that additional mechanisms, such as the inactivation of pro-apoptotic machinery, may also underlie the neuroprotective effect of AKT phosphorylation [146, 156].

\section{AKT and growth factor signalling}

AKT phosphorylation is downstream of the activation of multiple growth factor receptors (Fig. 1): for example, EGF and insulin-like growth factor 1 (IGF-1) stimulation of immortalised rat cells caused transient and sustained activation of AKT, respectively, which also increased cell viability [157]. AKT activation shares multiple upstream growth factor receptors with MEK/ERK signalling, and its alteration in models of HD has been attributed to similar mechanisms as alterations in MEK/ERK activation, namely inter- ference of GRB2 at the EGFR and tyrosine kinase A (TRKA) by mHTT [85, 87]. However, this interference does not explain the substantially augmented AKT response that is observed in many models of HD $[15,29,147,149]$. AKT has been identified as an integration point for several growth factor pathways, and therefore synergism between multiple pathways may be a mechanism for altered AKT observed in models of HD; for example, IGF-1, BDNF, NGF and transforming growth factor $\beta$ (TGF $\beta$ ) signalling have all been associated with modulating AKT activation [50, 91, 104, 110, 134, 137, 158-165].

IGF-1 stimulation in amino-terminal models of HD ameliorates mHTT toxicity and reduces nuclear inclusions, which is thought to be mediated by the direct phosphorylation of mHTT on serine 421 as a result of AKT activation [137]. IGF-1-induced AKT phosphorylation can restore the anterograde and retrograde transport of BDNF-containing vesicles that is lost in a mouse neuronal cell model of HD [104], therefore enhancing striatal BDNF neurotrophic support. Stimulation with IGF-1 was unable to fully rescue cells that carried an mHTT fragment with a phosphoresistant mutation on serine 421 [137]; however, there was still some IGF-1-associated survival in these cells, strengthening the probability that the neuroprotective effects of AKT act via multiple mechanisms in addition to direct mHTT phosphorylation.

Although AKT activation plays a role in enhancing the vesicular transport and release of BDNF [104], BDNF stimulation is also able to phosphorylate AKT [50, 91] and AKT activation has been found to contribute to BDNF-induced dopamine- and cAMP-regulated neuronal phosphoprotein (DARPP32) expression in MSNs [110]. The BDNF receptor, TRKB, is downregulated in several models of HD and in human HD brain [16, 91, 92, 148, 166], and may account for suppressed AKT activation in response to BDNF [148]. However, increased expression of the BDNF-responsive P75 NTR in models of HD and human HD brain may facilitate TRKB-mediated AKT activation following stimulation with BDNF [91]. The modulation of AKT activation is likely to rely on the integration of multiple input signals, therefore attempts to characterise and manipulate this pathway by targeting a single kinase may prove ineffective.

AKT has been identified as a point of convergence between EGF, IGF-1 and TGF $\beta$ signalling pathways $[162,165,167]$. TGF $\beta$ is a versatile regulator of cell growth, proliferation and apoptosis [164, 168]; mothers against decapentaplegic homolog (SMAD) proteins 


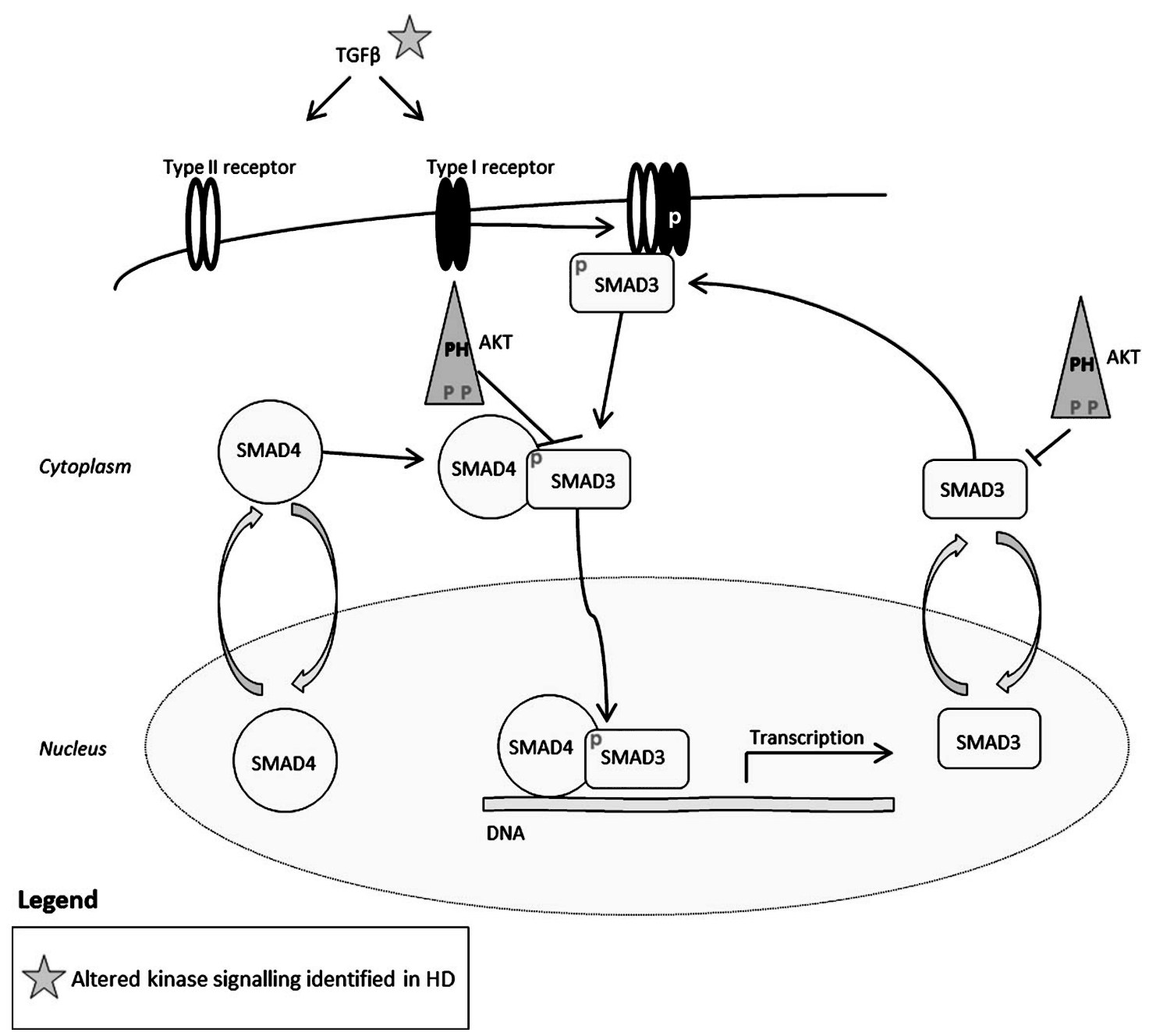

Fig. 4. Simplified cartoon depicting the basic mechanism of SMAD3 signalling in the TGF $\beta$ pathway and inhibition by AKT. TGF $\beta$ stimulates its Type I and Type II receptors, creating a hetero-tetrameric receptor complex. The Type II receptor phosphorylates the Type I receptor, which then allows the phosphorylation of receptor-regulated SMAD3, which is constantly shuttling between the nucleus and cytoplasm until anchor proteins recruit them to the active Type I receptor. Phosphorylated SMAD3 can bind to the Co-SMAD4, which is also consistently shuttling between nuclear and cytoplasmic compartments. The resulting SMAD3-SMAD4 complex then translocates to the nucleus where it may either bind directly to DNA to stimulate transcription, or will incorporate DNA binding cofactors (see [164, 193] for a review). Activated AKT binds to SMAD3 and sequesters it in the cytoplasm, thus preventing its phosphorylation, binding to SMAD4 and nuclear translocation; this effect is enhanced with IGF-1 stimulation, and attenuated with TGF $\beta$ stimulation $[162,163]$. The blue/grey star marks where altered kinase signalling has been identified in HD, but the evidence for the nature of the effect has been mixed.

and their interactions with AKT are key mediators of this pathway [162, 163] (Fig. 4), which can also be modulated by stimulation of the EGFR [169]. TGF $\beta$ can upregulate AKT and ERK [167] as well as proapoptotic members of the MAPK family [170]. As TGF $\beta$ signalling overlaps substantially with targets implicated in the pathogenesis of $\mathrm{HD}$, this pathway may contribute to altered kinase signal transduction and downstream effects such as transcriptional dysregulation. However, investigation of this pathway in the context of HD remains sparse. A reduction in circu- lating TGF $\beta$ in the blood of asymptomatic HD patients has been observed, and its presence had an inverse correlation with CAG repeat length [171]. A small reduction of serum TGF $\beta$ was identified in female R6/1 mice [150], but despite reduced cortical TGF $\beta 1$ in YAC128 and R6/2 mice, there was a slight increase in striatal TGF $\beta 1$ in these animals [171]. A human induced pluripotent stem cell (iPSC) model of HD was also found to have an upregulation of the TGF $\beta$ pathway, which could be restored to normal levels by replacing the expanded HTT CAG repeat with one of 
a non-pathogenic length [172]. In addition, increased TGF $\beta$ signalling has been identified in the hippocampus of a transgenic rat model of $\mathrm{HD}$ and in R6/2 mice, where it had an inverse effect on neural stem cell proliferation [173]. Given their association with the AKT pathway and evidence of dysregulation in models of HD, the TGF $\beta$ signalling pathway and the regulation of SMAD transcription factors may prove to be an interesting new mechanism contributing to transcriptional dysregulation and molecular pathogenesis in HD.

\section{PRO-APOPTOTIC PATHWAYS}

\section{The MAPKS}

The co-ordination of pro-survival and pro-apoptotic signalling networks regulates cell growth and differentiation [149], and contributes to cell fate following neuronal insult. MAPKs are a superfamily of serine/threonine protein kinases that mediate diverse cellular responses to external stimuli, such as proliferation, differentiation and apoptosis [174-176]. MEK/ERK signalling is the pro-survival branch of this family, whereas P38 and JNK are more strongly associated with a pro-apoptotic response. The phosphorylation of P38 and JNK occurs through a multi-tiered kinase cascade analogous to the phosphorylation of ERK, with different upstream activators (Fig. 5), and their localisation following activation is likely to determine the target substrate and consequent cell response [177].

\section{JNK signalling}

JNK signalling regulates transcription associated with the cell death response [178], and is activated in response to stimuli such as heat shock, ER stress and oxidative stress [88, 179-181]. JNK activation in turn phosphorylates and increases the activation of the transcription factor C-JUN [182]; as C-JUN is a part of the transcription complex activator protein 1 (AP1), the dysregulation of its activity via altered JNK signalling has widespread consequences for the regulation of many pro-apoptotic genes [183-185]. Increased JNK activation may also cause an impairment of axonal transport; JNK phosphorylates kinesin-1, reducing its binding affinity to microtubules and blocking axonal transport [186]. Chronic activation of JNK has been observed in both $\mathrm{AD}$ and $\mathrm{PD}$ as a major regulator of cell death $[187,188]$. In addition, mice lacking the CNSexpressed JNK3 have exhibited some neuroprotection against kainic acid-induced excitotoxicity [189, 190],

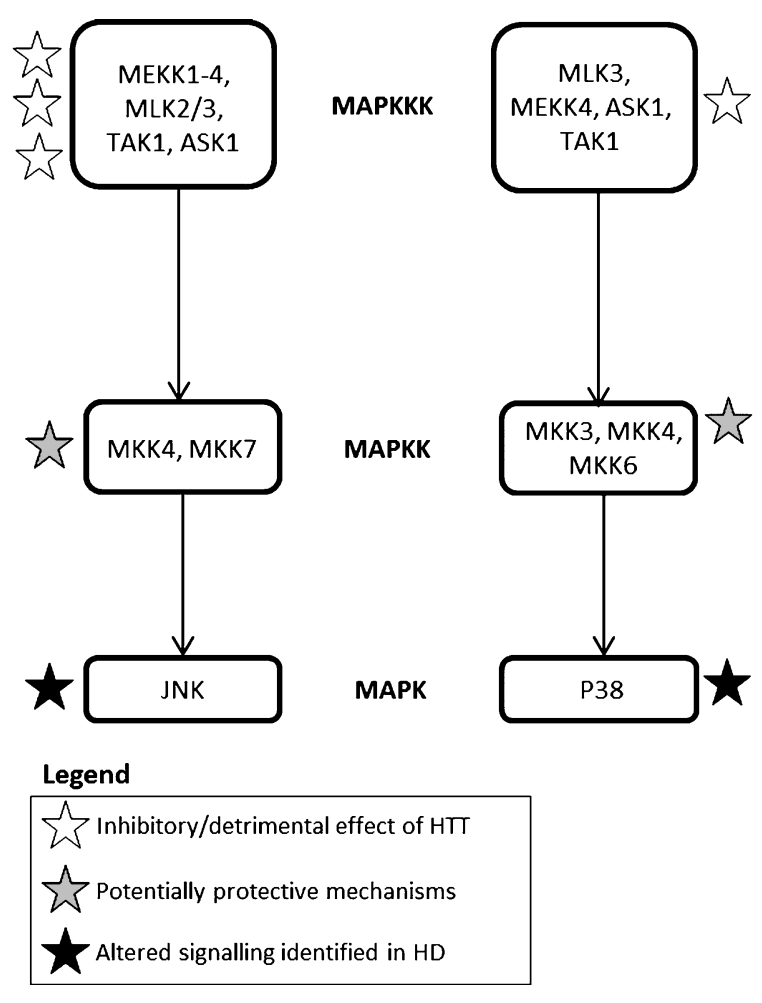

Fig. 5. The MAPK multi-tiered cascade. MAPKKKs upstream of JNK phosphorylate MKK4 and MKK7, which catalyse the phosphorylation and activation of JNK. Upstream activators of P38 phosphorylate MKK3 and MKK6, which in turn activate P38; MKK4 acts as a point of convergence between the two pathways and is able to phosphorylate both JNK and P38 (for a review, see [31]). Stars indicate points within the pathway that have been identified as being altered in models of HD, have been found to interact with HTT, or have alterations that may be protective. White stars represent inhibitory or detrimental effects of mHTT; blue/grey stars represent potentially protective mechanisms in HD; black stars mark where altered kinase signalling has been identified in $\mathrm{HD}$, but the evidence for the nature of the effect has been mixed.

although they do not appear to be protected against 3- nitropropionic acid (NP) neurotoxicity [139]. JNK3 signalling has an antagonistic relationship with the AKT signalling pathway [141]; JNK3 null mice have increased PI3K activity and enhanced AKT phosphorylation [191].

JNK has also been associated with several other growth factor-stimulated pathways and kinases (Fig. 1). For example, JNK can be phosphorylated by both EGF [192] and TGF $\beta$ [193-196], and both JNK and P38 can be enhanced by aberrant CDK5 activation in response to beta-amyloid (A $\beta)$ [197, 198]. However, in non-pathogenic contexts, CDK5 can promote survival via JNK inactivation [114]. JNK has also been found to stabilise P53 by phosphorylation, thus increasing its pro-apoptotic activity [199], and may 
also modulate other MAPKs (Fig. 8); JNK3 null mice had a suppressed P38 response to a kainic acid injection, and a less persistent ERK phosphorylation effect [189].

\section{$J N K$ in $H D$}

The majority of investigations into JNK signalling in models of HD have detected an upregulation of this pathway in response to mHTT (Table 3), and protein-protein networks constructed from published data have demonstrated a gain of function in the JNK pathway in HD [200]. These studies have focused primarily on transgenic cell lines and transgenic mice and the finding of increased JNK phosphorylation is fairly consistent. However, this is not the case for the $S t H d h^{Q 111}$ knock-in cell line. As an immortalised embryonic model, the $S t H d h^{Q 111}$ cell line may be more representative of very early developmental stages in HD pathogenesis, and the initial activation of compensatory pro-survival signalling pathways, such as AKT, may be attenuating pro-apoptotic JNK responses. Although increased JNK activity has been observed in YAC128 and YAC72 mice at relatively young ages [201], the equivalent has not yet been investigated in knock-in models of HD. It would therefore be of interest to longitudinally examine the activation of JNK over the life-span of a knock-in mouse model in order determine whether increased JNK phosphorylation is a disease-development specific phenotype, or is a result of truncated or overexpressed HTT.

Enhanced JNK phosphorylation is accompanied by increased caspase-3 activation, which can be suppressed with JNK inhibition [26]. The cleavage of mHTT by caspases has been associated with increased cellular toxicity and neurodegeneration $[9,61,62$, $105,202]$, and the inhibition of JNK phosphorylation has consistently been found to be protective against apoptosis and neurodegeneration in models of HD [26, 79, 203-205]. Targeting upstream activators of JNK has proven to be effective for JNK suppression and neuroprotection; for example, expression of a dominant negative form of MAPK-kinase 4 (MKK4) (Fig. 4) attenuated cell death in an immortalised murine hippocampal cell line [204]. The activation of the upstream regulator of JNK, MAPK-kinase-kinase 1 (MEKK1) (Fig. 4), reduces the solubility of polyQ peptides in a transgenic cell model of HD, and therefore stimulates the formation of mHTT intranuclear inclusions [206] (Fig. 8). However, in this model constitutively active MEKK1 did not activate JNK, and MAPK inhibitors had no effect on inclusion formation [206]. In addition, the overexpression of dominant negative mutants of MEKK1 and JNK-interacting protein 1 (JIP1) in a rat lentiviral model rescued the loss of DARPP-32 expression [207], but had no effect on intracellular mHTT inclusions or the expression of $c$ Jun [207]. Therefore MEKK1 activation is likely to be altering mHTT pathology via multiple mechanisms and signalling pathways in addition to JNK activation, and the targeting of multiple signalling pathways may be required to modulate a more substantial neuroprotective response.

\section{Mechanisms of increased JNK signalling in models of $H D$}

The impairment of JNK kinase signalling by mHTT is complex due to its occurrence at multiple points within the JNK signal transduction cascade (Fig. 5), including the inhibition of negative regulators, the phosphorylation of upstream activators, and the modification of cellular responses due to alterations in receptor expression. MLKs are a family of serine/threonine protein kinases that function as MAPKKKs to activate MAPKKs, which consequently activate JNK and P38 (Fig. 5) [35, 208, 209]. MLK2 is predominantly expressed in brain [210], and is specifically associated with activation of the JNK cascade [31, 35, 211-214]. MLK2 has an SH3 domain that is homologous to the SH3 domain of GRB2 [210]; HTT binds to MLK2 in a manner similar to its interaction with GRB2, and this association is lost with the presence of an expanded polyQ on mHTT [88, 205]. As MLK2 is constitutively active in its free form [215], HTT acts as an inhibitor of its activity and suppresses JNK activation; when this inhibitory association is lost due to the presence of mHTT, MLK2 is free to enhance pro-apoptotic JNK activation [88]. Expression of a dominant negative form of MLK2 could attenuate apoptosis in a hippocampal neuron-derived cell model (HN33) expressing expanded mHTT, and overexpression of amino-terminal HTT could partially rescue toxicity induced by MLK2 activation [205]. mHTT has also been found to enhance pro-apoptotic signalling via ER stress-dependent activation of apoptosis signal-regulating kinase 1 (ASK1) [216, 217]; another MAPKKK upstream of JNK signalling [31].

In addition to the hyperactivation of upstream kinases, Merienne et al. 2003 proposed that the expanded polyQ of mHTT alters the solubility of the JNK dual specificity phosphatase M3/6, therefore rendering it inactive and unable to attenuate JNK phosphorylation. Additionally, heat shock protein 70 (HSP70) activity is able to prevent the aggregation of M3/6 and reduce JNK activation; however 


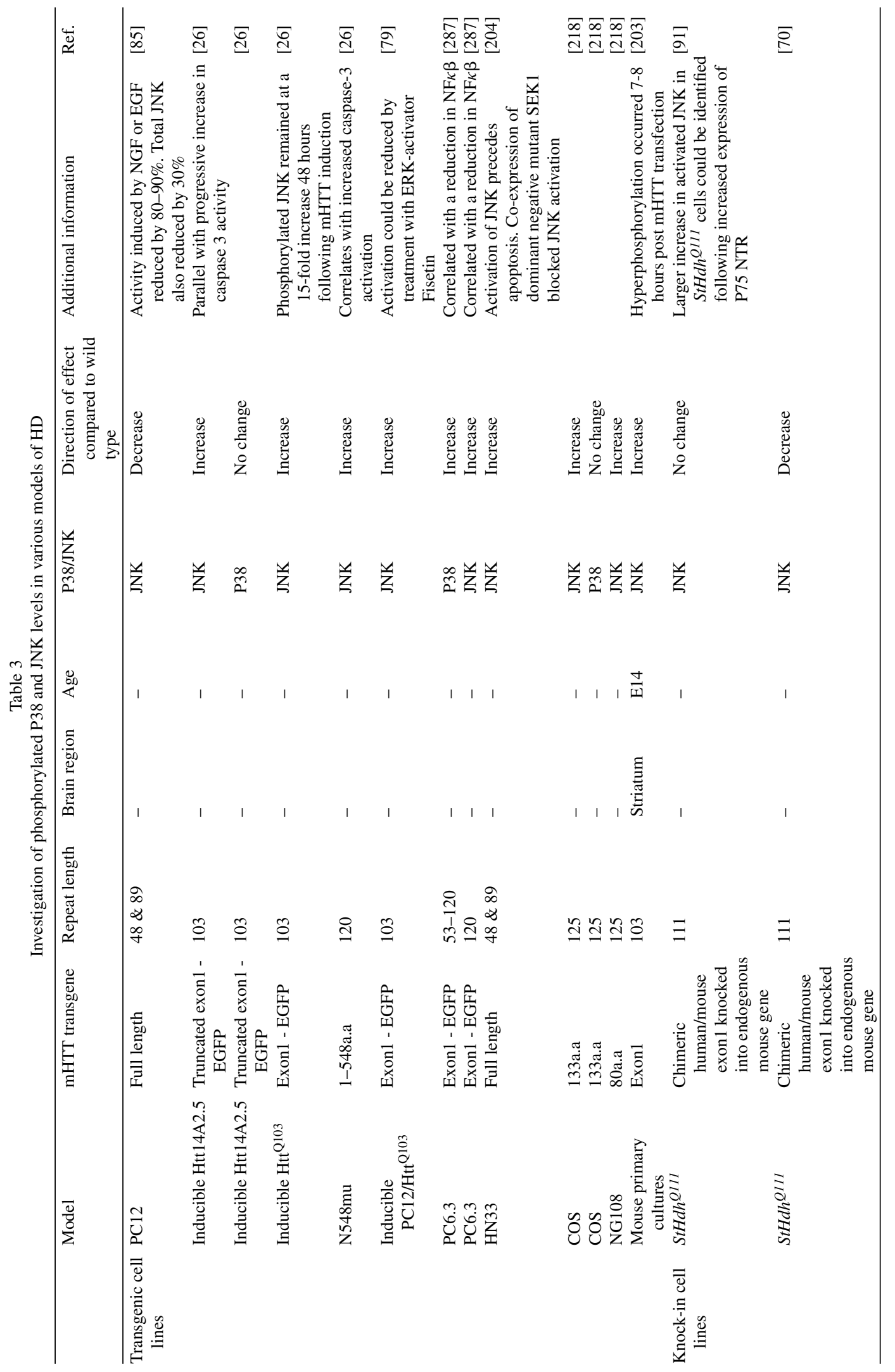




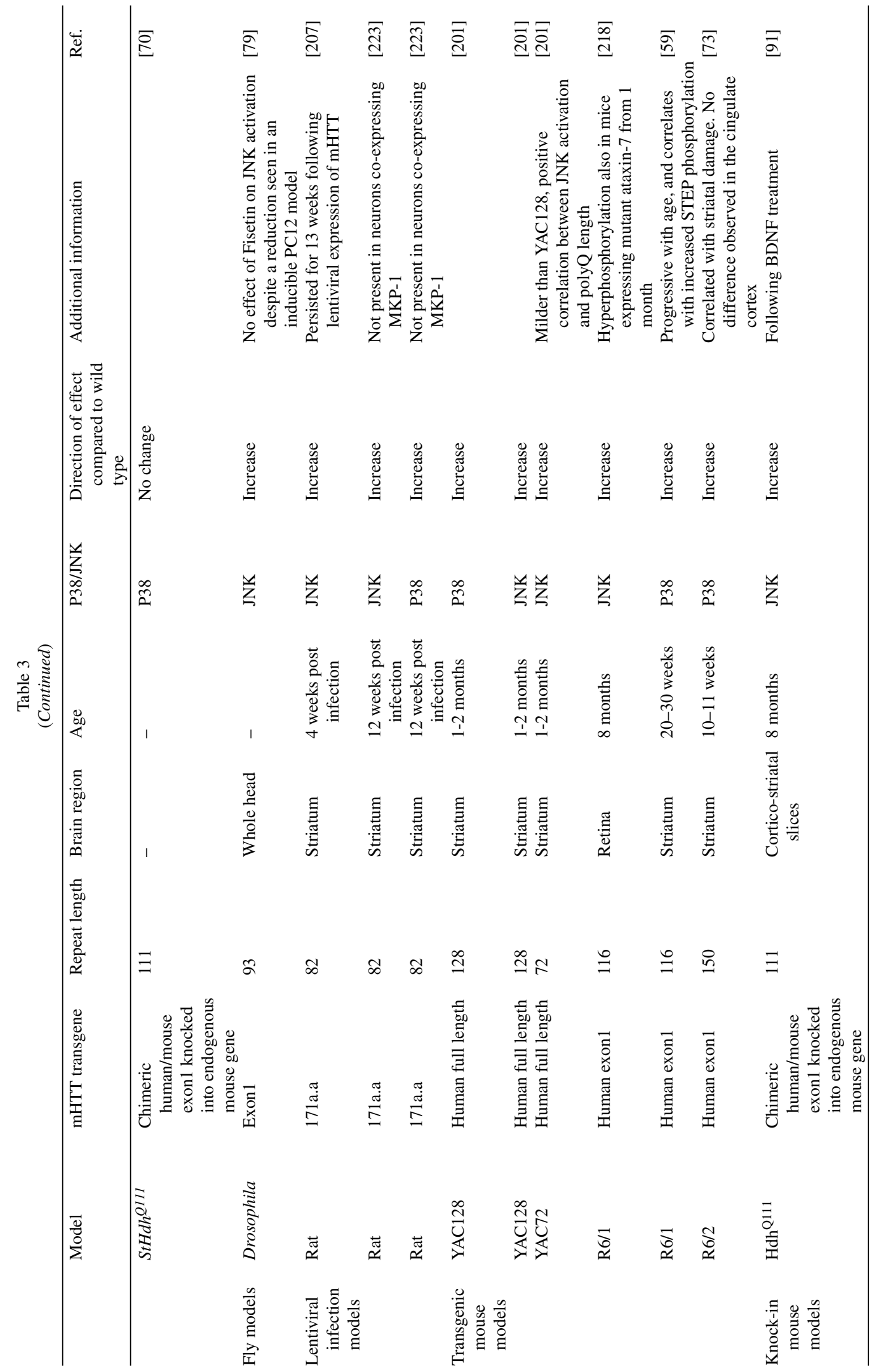


its expression is downregulated by mHTT, preventing its protective function [218]. Finally, the imbalance of P75 NTR and TRKB BDNF-responsive receptors has been proposed as a mechanism for enhanced JNK activation by altering the nature of cellular responses to BDNF [91]. Reducing the expression of P75 NTR in Hdh ${ }^{\text {Q111 }}$ mice attenuated JNK phosphorylation, whereas its overexpression in $S t H d h^{Q 111}$ cells enhanced JNK activation and decreased cell survival [91].

\section{P38 signalling}

P38 activity has been associated with multiple signalling pathways (Fig. 1), and has been identified as having both pro- and anti-apoptotic functions depending on which pathway substrates are engaged. P38 activation can be induced by TGF $\beta$ [194-196, 219] in order to selectively modulate gene responses dependent on P38-induced transcription factor regulation [164]. P38 activity can also be inhibited by AKT signalling [141], and can form a positive feedback loop for its activation by phosphorylation of the EGFR [220]. P38 acts in a similar way to JNK by enhancing P53 activity, albeit by a different mechanism; P38 blocks the interaction between P53 and its negative regulator, mouse double minute 2 homolog (MDM2), which would normally target P53 for degradation by the ubiquitin proteasome system [199, 221].

\section{P38 in models of HD}

P38 is commonly found to be increased in models of HD (Table 3), although several models have noted no difference in P38 phosphorylation in the presence of mHTT expression [26, 70, 218]. As the range of models that have been utilised to investigate P38 activity encompasses both transgenic and knock-in approaches as well as a variety of mHTT fragments and polyQ repeat lengths, it is difficult to determine a reason for the lack of P38 alteration in these models. However, as kinase signalling responses can be modulated by a variety of factors, such as cellular context, tissue type and environment, inconsistencies between laboratories and conditions may be unsurprising.

The increased activation of P38 identified in transgenic mouse models of HD correlates with the extent of striatal damage in these animals [59, 73] and contributes to the enhanced glutamate excitotoxicity observed in YAC128 mice [201]. Although P38 is increased in animal models of HD, the time point at which this occurs and its function remains under debate: alterations in P38 are observed in YAC128 mice from a relatively early age (1-2months) [201] and at an early pre-pathogenic time point (8 months) in $\mathrm{Hdh}^{\mathrm{Q} 111}$ knock-in mice [91]. However, Saavedra et al. (2011) suggest that in R6/1 mice, P38 accumulates with age and is not significantly enhanced until the advanced stages of disease in these animals (20-30 weeks). This progressive accumulation was correlated with the progressive inactivation of STEP [59]. Although enhanced P38 activation is considered to be pro-apoptotic, and its inhibition has shown to increase neuronal survival in several models of HD [222, 223], it has also been argued that P38 activation may be neuroprotective. R6 mouse models demonstrate neuronal dysfunction rather than substantial neuronal loss [224, 225], and this anti-apoptotic effect has been attributed to its co-ordination with upregulated pro-survival pathways such as AKT and ERK in these models [223, 226]. In addition, P38 can regulate $\mathrm{mHTT}$-induced serine/threonine protein kinase (SGK) activity, which, like AKT, has been to shown to regulate HTT toxicity by promoting the neuroprotective post-translational modification of serine 421 phosphorylation [227]. However, whether P38 will support pro- or anti-apoptotic signalling is likely to be dependent on cellular context and the activation of downstream substrates, and may fluctuate with disease progression.

\section{$M K P 1$}

MKP1 is a dual specificity phosphatase (DUSP), which is an immediate-early gene that is expressed in response to stressors such as oxidative damage or heat shock [228], and can target both JNK and P38. Its downregulation in models of HD is a potential mechanism for the enhanced P38 also observed in these models; MKP1 is reduced in R6/2 [223, 229] and in $\mathrm{Hdh}^{\mathrm{Q} 150}$ [230] brain, as well as in a primary cell model and in human HD post-mortem caudate [223]. Consequently, its overexpression is able to prevent mHTT-induced activation of JNK and P38, whereas ERK phosphorylation was not altered [223]. Furthermore, attenuating the activation of either JNK or P38 alone was not as effective in rescuing the neurotoxic effects of mHTT expression as the attenuation of both together [223], suggesting that the regulation of multiple signalling pathways is required to modulate cell survival in the presence of mHTT neurotoxic insult. Additional evidence for the role of MKP1 in regulating the pro-apoptotic $\mathrm{P} 38$ response in HD models includes its upregulation by treatment with BDNF [231] and with the histone deacetylase inhibitor, sodium butyrate, which has been shown to have neuroprotective effects in Drosophila and R6/2 models of HD [232, 233]. 
Targeting an upstream modulator of several pathways may be an efficacious approach to altering kinase signalling within multiple connected networks: however care must be taken when considering the potential long-term implications of this approach on HD neuropathology and on pro-survival signalling pathways.

\section{P53}

P53 is a key regulator of apoptotic machinery and tumour suppression through the co-ordination of cellular responses to stress [234, 235]. Upon cell stress, P53 is stabilised via several mechanisms (Fig. 6); it is deubiquitinated by ubiquitin carboxyl-terminal hydrolase 1 (USP1), thus rescuing it from degradation and increasing its activity [236], its activator peptidyl-prolyl cis-trans isomerase NIMA-interacting 1 (PIN1) can be phosphorylated by other DNA damage-activated kinases, such as ataxia telangiectasia mutated (ATM) and homeodomain-interacting protein kinase 2 (HIPK2), which then leads to a conformational change in P53 that promotes its accumulation [237-240] and its inhibitor, MDM2, is impaired, therefore preventing the promotion of P53 proteasomal degradation [36, 241]. In addition, active P53 translocates to cell nuclei where it can then enhance its own expression [36]. P53 activity can also be enhanced by JNK and P38, as previously described, and AKT signalling can also regulate P53 levels by the activation of MDM2 [242, 243] (Fig. 1). The overexpression of P53 in neuronal cultures elicits cell death, whereas P53 null mice have been shown to be mildly resistant to neurotoxicity [244, 245]. P53 therefore provides an additional pro-apoptotic target that may be dysregulated in HD, thus promoting cell death and neurodegeneration.

\section{P53 in models of HD}

Although it has been less thoroughly investigated than the other kinase pathways discussed above, P53 is consistently identified as upregulated in several cell and animal models of HD, as well as in human lymphoblasts and brain (Table 4), and genes downstream of P53 signalling are upregulated in both cell and mouse models of HD [240, 246]. High levels of P53 have been identified in human post-mortem HD brain, with high levels of P53 phosphorylation on serine 46, a post-translational mechanism associated with activation of P53 apoptotic function $[239,247]$ that can be induced by mHTT expression in vitro [240]. The role of P53 in HD-associated neurodegeneration has been

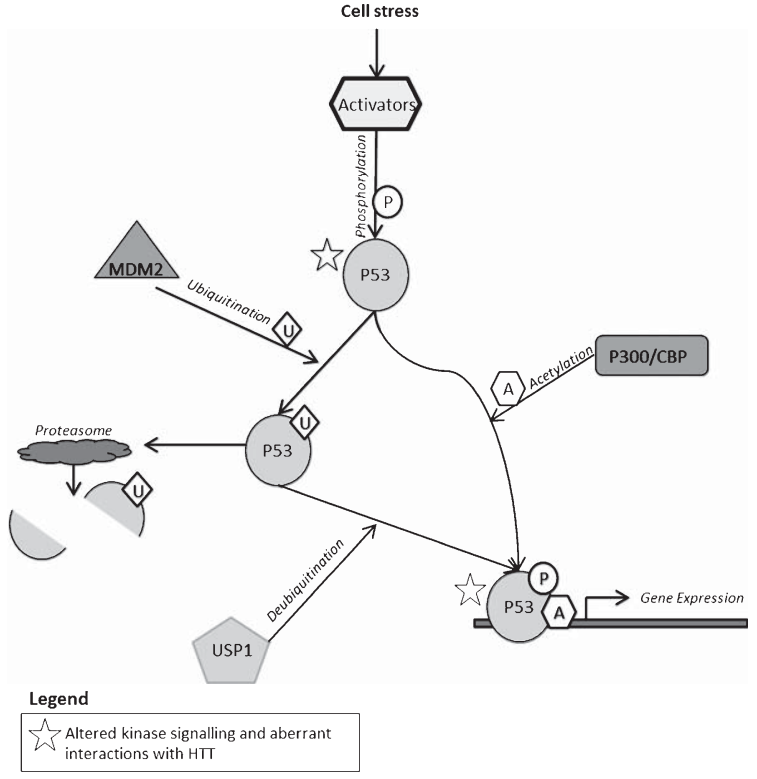

Fig. 6. Stabilisation of P53. P53 is phosphorylated by a variety of cell stress-induced kinases, such as ATM, JNK, PIN1, P38 and HIPK2. The activation of P53 by phosphorylation promotes nuclear localisation, where it acts as a transcription factor, and potentiates acetylation by $\mathrm{P} 300 / \mathrm{CBP}$, which augments DNA binding. MDM2 negatively regulates $\mathrm{P} 53$ by ubiquitination, which targets its for clearance by the proteasome. USP1 deubiquitinates P53, thus rescuing it from degradation and stabilising it for activation. Active P53 is also able to enhance its own gene expression [36, 236-240]. White stars indicate where altered kinase activation and aberrant interactions with mHTT that are detrimental to cell survival have been identified.

associated with several mechanisms including mitochondrial membrane depolarisation and cytotoxicity [248]. The binding of P53 to mitochondria is 3x higher in $S t H d h^{Q 111}$ cell lines compared with their wild type counterparts, which may be regulated by the activity of the mitochondrial fission protein dynamin-related protein (DRP1) [249]; DRP1 inhibition reduced this association and increased the survival of R6/2 mice, and reduced the number and size of intracellular striatal aggregates [249].

P53 interacts with nuclear factor kappa-light-chainenhancer of activated $\mathrm{B}$ cells $(\mathrm{NF} \kappa \beta)$ (Fig. 8), resulting in the suppression of $\mathrm{NF} \kappa \beta$ expression and activity; this subsequently decreases the expression of microRNA miR-146a in StHdh ${ }^{Q 111}$ cell lines and R6/2 striatum, negatively impacting transcriptional regulation [250]. The expression of negative regulators of P53, MiR-150 and MiR-125b, were also suppressed in these models, providing a mechanism for prolonged P53 activation and cellular dysfunction [250]. P53 activation has been described as providing a transient pro-survival response in MSNs following 


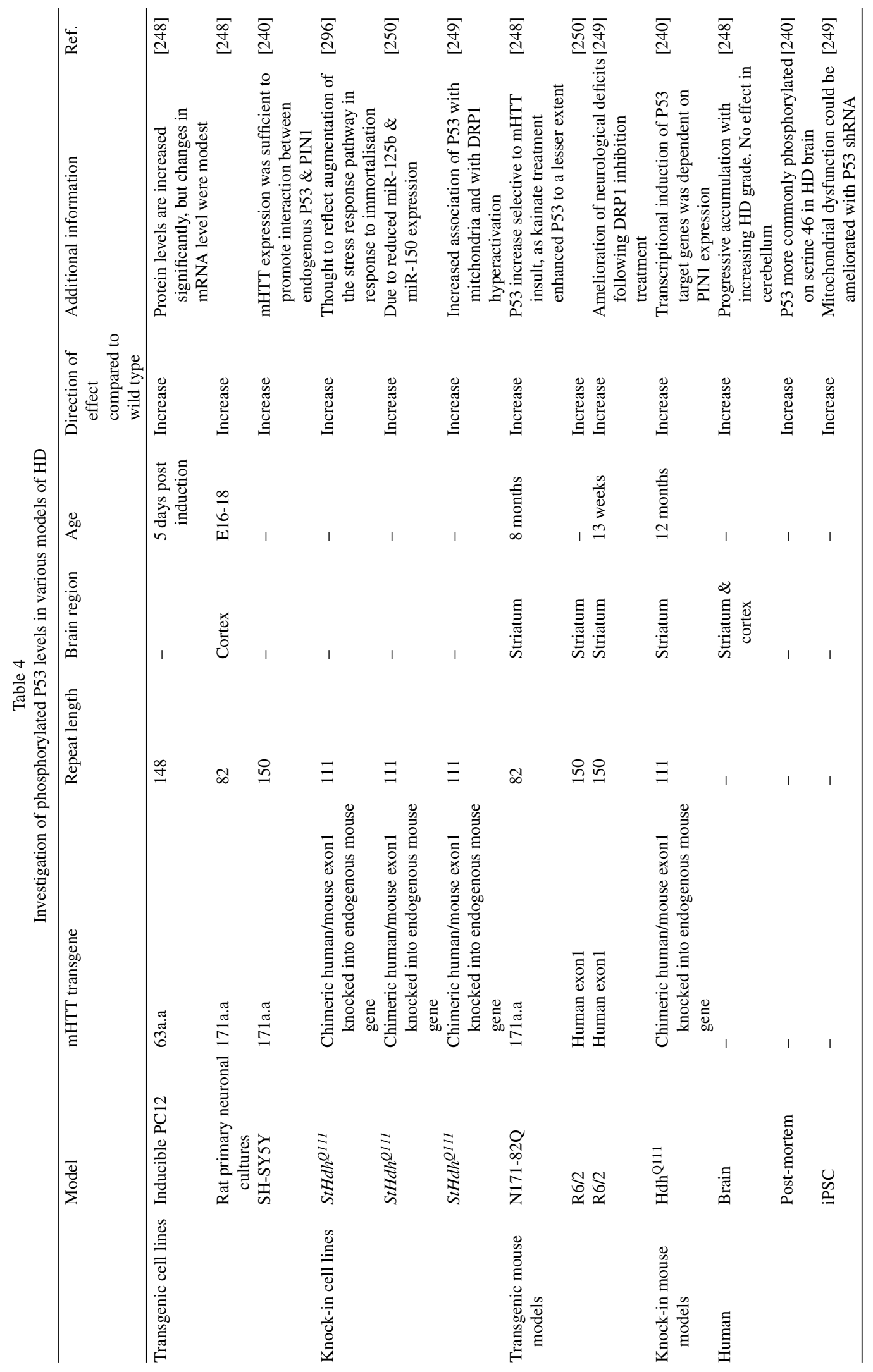




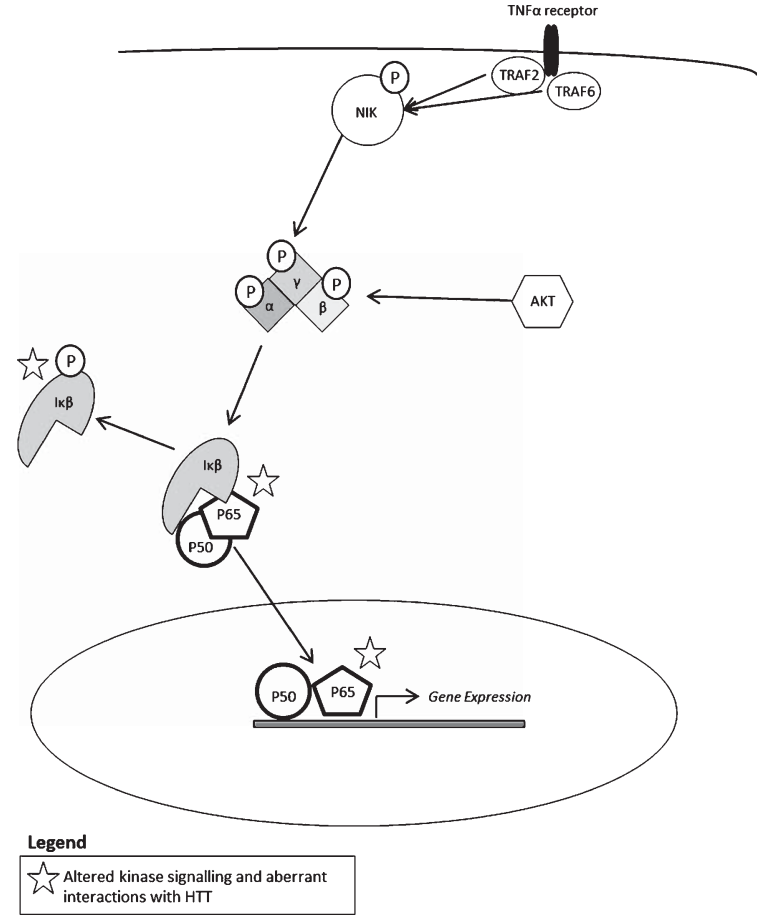

Fig. 7. IKK/NF $\kappa \beta$ cascade. The IKK complex, consisting of $\alpha, \beta$, and $\gamma$ subunits is phosphorylated by kinases downstream of receptor activation by cytokines; the most common of which is TNF $\alpha$, which phosphorylates TNF receptor associated factors, TRAF2 and TRAF6. These consequently activate NF $\kappa \beta$ inducing kinase (NIK), which phosphorylates the IKK complex. IKK may also be phosphorylated by AKT downstream of alternate signalling pathways, such as following EGF and platelet derived growth factor (PDGF) stimulation. NF $\kappa \beta$ is present in the cytoplasm as a three unit complex composed of P65, P50 and $\mathrm{I} \kappa \beta$ subunits. Activated IKK phosphorylates $\mathrm{I} \kappa \beta$, resulting in its ubiquitination and degradation. The P65 and P50 subunits are then freed for nuclear translocation and transcriptional regulation [88, 134, 250, 261, 263-267, 269]. White stars indicate where altered kinase activation and aberrant interactions with mHTT that are detrimental to cell survival have been identified.

nuclear stress due to a mHTT-associated impairment in nucleolar and ribosomal integrity [251], although prolonged P53 activity ultimately leads to cell death and neurodegeneration.

The silencing or inhibition of P53 has been shown to be neuroprotective in models of HD; silencing P53 in the $S t H d h h^{Q 111}$ cell model reduced cell death and the number of cells with fragmented mitochondria [249], and its deletion suppressed retinal degeneration in Drosophila and rescued behavioural abnormalities in R6/2 mice [248]. Reducing P53 also abolished neuronal death in primary striatal cell cultures and ameliorated the toxicity induced by the removal of HTT phosphorylation of serines 1181 and 1201 [121].

\section{P53 and huntingtin}

Importantly, mHTT has been shown to directly interact with P53 in a manner that alters the expression and activity of both [240, 248, 252-256] (Fig. 8). mHTT can sequester P53 within intranuclear inclusions [232, 254], and they may interact via the amino-terminal region of mHTT [248, 252, 253], which may alter P53 transcriptional activity [252]. Therefore, although P53 activity may be enhanced in HD, the mechanism by which it regulates transcription and apoptosis under normal cellular stress conditions may be aberrantly affected by mHTT, further complicating this mechanism. The HTT gene carries three potential P53responsive elements, which promote the expression of HTT upon P53 activation [255, 256]. As such, the expression of HTT is lower in $\mathrm{Hdh}^{\mathrm{Q} 140}$ mice deficient in P53 [256]. However, although inhibition of P53 may provide a two-pronged neuroprotective mechanism by suppressing pro-apoptotic pathways and reducing the cellular level of toxic mHTT, Ryan et al. 2006 demonstrated that P53 knockout $\mathrm{Hdh}^{\mathrm{Q} 140}$ mice had considerably more striatal intracellular inclusions than those expressing P53. Whether mHTT inclusions are neurotoxic remains debatable: however, aggregation requires high levels of toxic mHTT species [257] and accumulation of aggregates over time may be disruptive to cell function. Therefore inhibition of P53 may not provide effective long-term neuroprotection. mHTT has also been proposed as an upstream inducer of P53: expression of mHTT in SH-SY5Y neuroblastoma cells was sufficient to promote the interaction between P53 and one of its inducers, PIN1, resulting in P53 phosphorylation, and increased protein levels of another P53 modulator, HIPK2 [240].

\section{INFLAMMATORY SIGNALLING PATHWAYS}

$I K K \& N F \kappa \beta$

Neuroinflammation is a primary component of several neurodegenerative diseases [17, 258], and may promote either pro-survival or pro-apoptotic cell mechanisms depending upon the context and duration of pathway activation [19]. Both $\mathrm{Hdh}^{\mathrm{Q} 150}$ and R6/2 mouse models exhibit enhanced chronic neuronal proinflammatory responses to systemic inflammation that exacerbate motor and cognitive dysfunction [18], and human macrophage and monocyte cultures showed a hyper-reactive inflammatory cytokine response to lipopolysaccharide stimulation that could be attenuated with the lowering of mHTT expression [259]. 


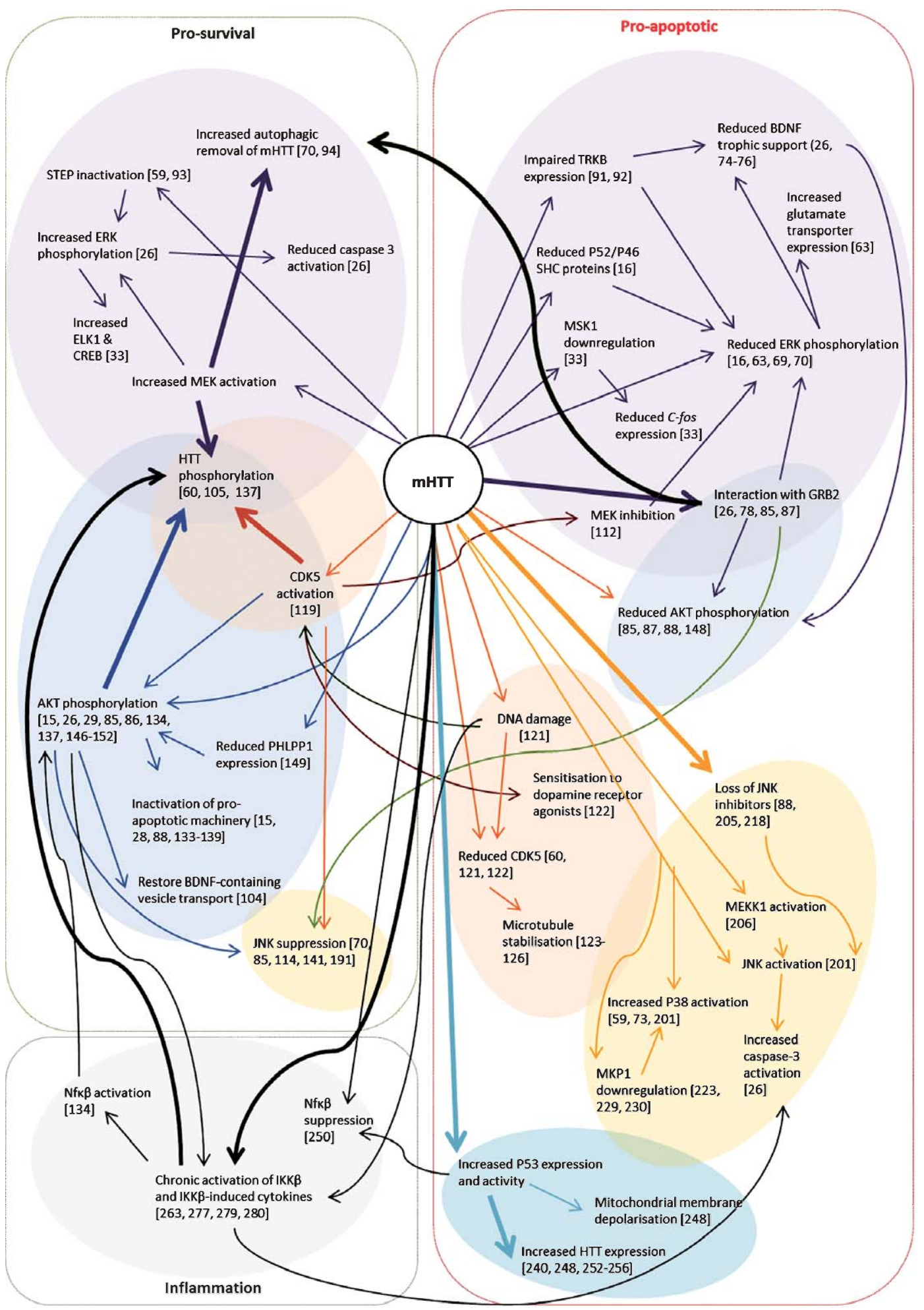

Fig. 8. Schematic displaying the interplay of mHTT with various kinase signalling pathways implicated in HD. Distinct pathways are grouped into separately shaded ellipses, which overlap where the consequences of mHTT disruption overlap. Weighted arrows indicate direct interactions with HTT or mHTT. Alterations in several signalling pathways result in both pro- and ant-apoptotic responses, depending on the model investigated, cellular context and experimental conditions employed. 
However, very mild chronic inflammation had no effect on disease progression in YAC128 mice [260], indicating that the role of neuroinflammation in HD could be highly variable and dependent on the regulation of multiple factors. The IKK/NF $\kappa \beta$ signalling pathway is a prominent regulator of neuroinflammation, and typically promotes cell survival and growth [19, 261-263]. IKK is composed of three subunits; IKK $\alpha$ and IKK $\beta$, which are homologous catalytic subunits, and IKK $\gamma$, a regulatory subunit [263] (Fig. 7). Phosphorylation of the IKKs has been shown to occur in response to tumour necrosis factor alpha (TNF $\alpha)$ stimulation, and in response to other growth factor-stimulated pathways via AKT activation [264-268] (Fig. 8). NF $\kappa \beta$ is present in the cytoplasm as an inactive complex of P50 and P65 subunits, bound by nuclear factor of kappa light polypeptide gene enhancer in B-cells inhibitor $(\mathrm{I} \kappa \beta)$ proteins $[261,262]$. The activated IKK complex phosphorylates the $\mathrm{I} \kappa \beta$ proteins, which targets them for ubiquitination and degradation. This subsequently frees the P50 and P65 subunits for translocation to cell nuclei where they activate transcription $[88,134,269$, 270] (Fig. 7).

Acute IKK $\beta$ activation typically invokes cellular pro-survival responses, whereas chronic elevation of IKK $\beta$ has been associated with neurodegenerative processes [19]. Chronic IKK $\beta$ activation can be induced via DNA damage [271], and a variety of stimuli activates the $\mathrm{NF} \kappa \beta$ pathway, including cytokines, injury and seizure [272]. Neuronal damage as a result of chronic IKK $\beta$ elevation has also been proposed to be a result of an excessive inflammatory response in adjacent astrocytes [18] as well as altering signalling in neurons themselves. Activation of the IKK $\alpha$ subunit is more commonly associated with neuroprotective mechanisms: for example, activation has been shown to inhibit pro-apoptotic P53 and IKK $\beta$ activity [273, $274]$, and to regulate IKK $\beta$-dependent expression of pro-inflammatory cytokines in immune cells [275]. It is also required for the promotion of memory consolidation and synaptogenesis in the hippocampus [276].

\section{IKK in $H D$}

Excessive IKK $\beta$ has been observed in several cell and mouse models of neurodegenerative diseases, including AD, MS, PD and HD [19, 277, 278]. HD patients also exhibit chronically increased levels of $\mathrm{IKK} / \mathrm{NF} \kappa \beta$ pathway-induced inflammatory cytokines $[263,277]$ in blood serum and in the CNS prior to symptom onset, as well as hypersensitivity of immune cells $[17,259]$. Elevated IKK $\beta$ is present in HD cell culture models and in R6/2 mouse brain, which par- allels the enhanced levels of inflammatory cytokines also detectable in these mice [277, 279]. However, increased IKK $\beta$ is identified only in the striatum of $\mathrm{Hdh}^{\mathrm{Q} 150}$ mice $[277,280]$. While exon 1 of mHTT was able to directly interact with IKK $\gamma$ in an inducible PC12 cell line expressing mHTT in a manner which promoted the assembly and activation of the full IKK complex, full length mHTT was unable to activate IKK $[277,281]$. The gradual accumulation of toxic aminoterminal mHTT fragments in the striatum of the full length $\mathrm{Hdh}^{\mathrm{Q} 150}$ model was proposed as a mechanism for the difference in IKK activation between mouse models $[277,280]$. However, more recently an interaction between IKK $\gamma$ and endogenous full length mHTT has been demonstrated in human-derived macrophage and monocyte cultures [259]. Consistent with a proapoptotic role of IKK $\beta$ in models of HD, blocking IKK $\beta$ activity prevented the degeneration of MSNs in cell culture and brain slice assays [277], and its knock down in microglia reduced neuroinflammatory and neurotoxic responses to kainic acid in hippocampal neurons [282].

The neurotoxic effects of elevated IKK $\beta$ have been associated with its role in the increased cleavage of HTT and mHTT in response to DNA damage; DNA damage accumulates with age and disease development, which activates caspases and reduces levels of anti-apoptotic protein B-cell lymphoma-extra large (BCL-XL) via activation of IKK $\beta$ [271]. The creation of additional mHTT amino-terminal fragments as a result of enhanced caspase activation may then result in the prolonged activation of IKK by the interaction of mHTT with the IKK $\gamma$ subunit, therefore creating a toxic feedback loop. Inhibition of IKK $\beta$ or enhancement of IKK $\alpha$ prevented caspase activation and HTT proteolysis, which resulted in the promotion of neuronal survival [101, 271]. Deletion of IKK $\beta$ from microglia reduced the extent of neurodegeneration in a chemical model of neurodegeneration [282], and astrocytes from the R6/2 mouse model exhibit higher IKK activity, which conferred a more damaging effect on adjacent neurons during inflammation [18]. Blocking IKK activity reduced the toxicity caused by R6/2 astrocytes and improved cognitive function and motor co-ordination [18].

\section{IKK and HTT phosphorylation}

The phosphorylation of HTT on serines 13 and 16 may be regulated by IKK $\beta$ activity; however the mechanism by which this occurs is under debate $[96,97$, 283]. Initially, Thompson et al. 2009 proposed that IKK $\beta$ phosphorylates HTT on these serines, which 
resulted in enhanced nuclear localisation, proteolysis and clearance by the proteasome and lysosome, and phosphorylation of mHTT by this process was less efficient. Enhanced mHTT proteolysis would firstly act as a neuroprotective mechanism by increasing the clearance of mHTT, consistent with the neuroprotective effect of acute IKK $\beta$ activation. However, chronic IKK $\beta$ activation and mHTT proteolysis would result in the accumulation of nuclear toxic amino-terminal fragments and the acceleration of wild type HTT turnover [96, 271]. The treatment of N171-82Q transgenic HD mice with the HDAC inhibitor $4 \mathrm{~b}$ increased the expression of genes encoding components of the IKK complex, and increased the phosphorylation of HTT at serine 16 and threonine 3 , as well as promoting the expression of genes associated with autophagy [283]. Treatment with the HDAC inhibitor also prevented the formation of mHTT aggregates, and improved motor and cognitive performance [283], therefore supporting a potentially neuroprotective role for enhancing IKK signalling.

Conversely, the inhibition of IKK $\beta$ has also been found to increase the phosphorylation and nuclear localisation of HTT [97, 284]. Increased IKK $\beta$ activity has been correlated with increased PP2A phosphatase activity [285], which can dephosphorylate serine 421 of HTT [286], thus increasing its nuclear accumulation. Whether IKK signalling is most likely to exert neuroprotective or neurotoxic effects remains unclear, and the nature of its activation is likely to be a result of the balance between individual contributions from the three subunits of the IKK complex, as well as the cellular context and activities within other pathways. Whether the phosphorylation of HTT on serines 13 and 16 is neuroprotective also remains under debate; it has been found to promote HTT accumulation in cell nuclei, to impair nuclear transport and it correlates with disease progression in $\mathrm{Hdh}^{\mathrm{Q} 140}$ mouse striatum [98], whereas in BACHD mice it appears to be neuroprotective [95].

Dysregulation of IKK signalling has therefore been consistently identified as a modulating factor in the progression of HD by influencing aberrant inflammation responses, and by direct interaction with the mHTT protein. However, the role of IKK $\beta$ in HTT phosphorylation remains to be elucidated, as both its activation and inhibition are able to elicit similar neuroprotective phosphorylation of HTT [96, 97, 271, 284]. As IKK can be regulated by multiple signalling pathways, such as AKT [264, 268] and TNF $\alpha$ [134], model-dependent alterations in activity within these pathways may contribute to the cellular response to
IKK signalling. The individual subunits of the IKK complex appear to have differential roles for cell survival and exhibit multiple patterns in models of HD [101, 271], therefore characterisation and the specific targeting of individual IKK subunits may be required to more fully understand the role of IKK $\beta$ in HD and to elicit effective neuroprotection.

\section{$N f \kappa \beta$ in $H D$}

Although formation of the inflammatory IKK complex elicits activation of $\mathrm{NF} \kappa \beta$ (Fig. 7), the majority of $\mathrm{NF} \kappa \beta$ signalling provides a pro-survival signal [134], and a lack of $\mathrm{NF} \kappa \beta$ signalling can be pro-apoptotic: for example, mice lacking the P50 subunit of $\mathrm{NF} \kappa \beta$ suffer increased 3-NP induced striatal damage and motor dysfunction [272]. As with many of the other kinase signalling pathways discussed here, the effects of mHTT on NF $\kappa \beta$ are varied, and whether or not $\mathrm{NF} \kappa \beta$ generally plays a neuroprotective role in models of HD remains unclear.

A reduction in $\mathrm{NF} \kappa \beta \mathrm{P} 65$ has been identified in $S t H d h^{Q 111}$ cells and in R6/2 striatum as a result of negative regulation by increased P53 activity [250], as well as in PC6.3 cells expressing mHTT [287]. However, StHdh ${ }^{Q 111}$ cells have increased responsiveness of $\mathrm{NF} \kappa \beta$ to stimulation by its activator interleukin 1 beta (IL-1 $\beta$ ) [277], and increased nuclear concentrations of $\mathrm{NF} \kappa \beta \mathrm{P} 65$ have been identified in $\mathrm{R} 6 / 2$ cortex and striatum at 8 weeks of age [101]. In this context, increased $\mathrm{NF} \kappa \beta$ signalling was found to be pro-apoptotic; blocking NF $\kappa \beta$ activity reduced $\mathrm{mHTT}$ induced toxicity in cultured cells [277]. Aberrant NF $\kappa \beta$ has also been observed in R6/2 mouse astrocytes as a result of increased IKK activity; however there was no difference in R6/2 neurons or microglia [18]. Increased astrocytic NF $\kappa \beta$ was also present in human HD caudate [18]. Similar to the $S t H d h^{Q 111}$ model, R6/2 astrocytes exhibited an increased $\mathrm{NF} \kappa \beta$ response following treatment with TNF $\alpha$ or IL-1 $\beta$, including the induction of stronger $\mathrm{NF} \kappa \beta$-DNA binding [18].

Although $\mathrm{NF} \kappa \beta$ activity has been regarded as a pro-apoptotic inflammatory mechanism in $\mathrm{HD}$, its upregulation via activation by an agonist for the ER chaperone protein, sigma 1 receptor, protected PC6.3 cells from the toxic effects of mHTT by increasing cellular antioxidants and reducing oxidative stress [288]. $N F \kappa \beta$ activation and function may also fluctuate over time; Di Pardo et al. 2013 demonstrated that monocyte-derived macrophages from pre-symptomatic HD patients had $\mathrm{NF} \kappa \beta$ activation similar to controls and higher than those taken from symptomatic patients: post-mortem brain tissue exhib- 
ited a similar changing profile of $\mathrm{NF} \kappa \beta$ dependent on the stage of neurodegeneration. Activation of $\mathrm{NF} \kappa \beta$ promotes pro-inflammatory macrophage polarisation [289], and may therefore provide neuroprotection following acute $\mathrm{NF} \kappa \beta$ activation, which then elicits damaging neuronal effects as a result of chronic activation. The subsequent reduction in $\mathrm{NF} \kappa \beta$ may be a result of a compensatory anti-inflammatory cascade [289]; the P50 subunit promotes the production of antiinflammatory cytokines, which promote formation of a P50/P50 homodimer that inhibits $\mathrm{NF} \kappa \beta$ activity [290, 291]. A reduction in $\mathrm{P} 65 \mathrm{NF} \kappa \beta$ later in the disease course may therefore be a result of preferential P50 activation [289]. Additionally, the reduction may be due to the sequestration of NF $\kappa \beta$ into mHTT neuronal aggregates upon disease progression [250]. This phasic alteration in $\mathrm{NF} \kappa \beta$ has also been observed in cell models of HD: upon mHTT induction, $\mathrm{NF} \kappa \beta$ is initially enhanced, but decreases following aggregate formation during disease progression [292, 293]. Kinase activation should therefore not be considered as a static characteristic that is present over the course of a disease, but fluctuations in activation state are likely to contribute to their pro-apoptotic or pro-survival function, as well as influence the development of molecular pathogenesis.

As the IKK/NF $\kappa \beta$ pathway does not act in isolation; time-related alterations in this pathway are likely to also impact upon multiple other signalling pathways. For example, AKT has been identified as a kinase upstream of IKK activation [264, 268] (Figs.1 and 8), however the phosphorylation of AKT has also been demonstrated as being downstream of $\mathrm{NF} \kappa \beta$ [134], which has implications for the regulation of pro-survival signalling pathways during disease progression. The NF $\kappa \beta$-regulated activation of macrophages also affects the number of TGF $\beta$ producing cells [289], and its activity as a transcription factor regulates the expression of inflammatory mediators, such as $\mathrm{TNF} \alpha$ and IL-1 $\beta$ [18], and therefore may be a major regulator responsible for influencing neurotrophic signalling, and consequently cell fate.

\section{CONCLUSION}

Kinase signalling pathways are fundamental to cell death and survival and hence their operation is likely to be important in the cell dysfunction and death seen in neurodegeneration. It is notable that whilst multiple kinases and signal transduction pathways have been implicated in the regulation of neuronal survival in
HD, very few demonstrate a single coherent pattern of activation. This may be a result of kinase signalling pathways commonly being considered in isolation: multiple points within the cell signalling network are likely to contribute to cell fate and dysfunction. A lack of replication across models and techniques used to investigate kinase signalling in HD has also contributed to the difficulty in clarifying the role of kinase signalling pathways in HD. For example, differences in mouse strain and genetic background may contribute to the equilibrium and regulation of kinase signalling in different models, and different stages of HD progression may also differ with respect to their kinase signalling pathways. As complex and dynamic mechanisms that potentially alter with age and disease progression, appropriate longitudinal investigation of kinase signalling pathways in HD may prove useful.

Additionally, signalling in multiple pathways integrate downstream of a single growth factor stimulus, and multiple stimuli share similar common signalling pathways (Fig. 1). Thus different kinetics of stimulation and response, as well as different cellular contexts, are required in order to differentiate these signals [189, 294, 295]. For example, the magnitude and duration of ERK activity can determine whether or not it provides a pro-apoptotic signal [294], and the rapidity of ERK dephosphorylation has been correlated with the extent of neuroprotection that activation in this pathway may provide [189]. Consequently, treatment with the same stimulus, i.e. a growth factor or expression of mHTT, may result in different responses in different contexts, as has been commonly observed between models of HD.

The multiple stages at which kinase signalling can be altered by mHTT further adds to the complexity of signalling networks in HD: mechanisms that contribute to the dysregulation of kinase signalling pathways in HD include the disruption by mHTT at growth factor receptors [26, 63, 78, 85-87, 91], aberrant interactions with regulatory factors [33, 59, 88, 205, 216, 217, 240] and direct interaction with the mHTT protein itself [60, 240, 248, 252-256], which can in turn alter mHTT function and clearance by post-translational modifications such as phosphorylation [60, 88, 105, 121, 137].

MEK/ERK, CDK5/P35 and AKT signalling pathways are typically considered to be pro-survival pathways, although whether they are enhanced in models of HD as a compensatory response mechanism remains unclear. Activation of MEK/ERK and CDK5 has been demonstrated to be both neuroprotective and pro-apoptotic, depending on whether stimulation 
is chronic or acute and the presence of additional modulating factors $[116,122]$. The activation of proapoptotic signalling pathways in models of HD has been shown to be either upregulated, consistent with neuronal loss, or to exhibit no change. JNK activation has not yet been investigated as thoroughly as AKT or ERK signalling in HD and to date there is no evidence of its activation in human tissues or cell lines. The relationship between inflammatory kinases and additional neuroprotective or neurotoxic mechanisms is complex, and likely to be dependent on cellular context, synergistic associations with multiple signal transduction pathways and whether any inflammatory response is acute or chronic. Similar to the regulation of pro-survival and pro-apoptotic pathways, the characteristics and neuroprotective role of this pathway in HD is likely to depend on neuronal development and disease progression.

The understanding of signalling pathway networks in HD has implications for therapeutic targeting; for example, the differentiation between neuroprotective effects of acute activation and chronic inflammatory pathways would be important in order to avoid inhibiting early protective activation of these pathways. In addition, the differential activation of multiple pathways that occurs with disease progression may influence the point at which particular kinases may be targeted. Altering the activity of one kinase is likely to have effects on multiple others, thus an improved understanding of the integration of a network of pathways in different cellular contexts would be useful to construct a multi-pathway targeting approach.

In conclusion, the dysregulation of multiple kinase signalling pathways contributes to HD pathogenesis, including enhanced pro-apoptotic signalling and compensatory pro-survival mechanisms. The balance between these pathways and alterations over time may regulate disease progression and cell fate. However, inconsistencies in the pattern of kinase signalling in models of HD make any firm conclusions about individual pathways difficult to draw. The consideration of a dynamic network of multiple signalling pathways over time and in different cellular contexts may be beneficial in clarifying the role of various kinases in models of HD and to uncover new, potentially efficacious therapeutic targets.

\section{CONFLICT OF INTEREST STATEMENT}

The authors declare they have no conflicts of interest.

\section{REFERENCES}

[1] Martin JB, Gusella JF, Ronthal M, Herzog A, Flier JS, Amir S. Huntington's Disease - Pathogenesis and management. N Engl J Med. 1986;315(20):1267-76.

[2] Myers RH, Sax DS, Schoenfeld M, Bird ED, Wolf PA, Vonsattel JP, White RF, Martin JB. Late onset of Huntington's disease. J Neurol Neurosurg Psychiatry. 1985;48(6):530-4.

[3] Novak MJU, Tabrizi SJ. Huntington's disease. BMJ. 2010;341(c3109):34-40.

[4] Vonsattel JPG, DiFiglia M. Huntington disease. J Neuropathol Exp Neurol. 1998;57(5):369-84.

[5] Wexler NS. Huntington's disease: Advocacy driving science. Annu Rev Med. 2012;63:1-22.

[6] Politis M, Pavese N, Tai YF, Tabrizi SJ, Barker RA, Piccini P. Hypothalamic involvement in Huntingtons disease: An in vivo PET study. Brain. 2008;131(11):2860-9.

[7] Rosas HD, Salat DH, Lee SY, Zaleta AK, Pappu V, Fischl B, Greve D, Hevelone N, Hersch SM. Cerebral cortex and the clinical expression of Huntington's disease: Complexity and heterogeneity. Brain. 2008;131(4):1057-68.

[8] Scahill RI, Hobbs NZ, Say MJ, Bechtel N, Henley SMD, Hyare H, Langbehn DR, Jones R, Leavitt BR, Roos R a C, Durr A, Johnson H, Lehéricy S, Craufurd D, Kennard C, Hicks SL, Stout JC, Reilmann R, Tabrizi SJ. Clinical impairment in premanifest and early Huntington's disease is associated with regionally specific atrophy. Hum Brain Mapp. 2013;34(3):519-29.

[9] DiFiglia M. Aggregation of huntingtin in neuronal intranuclear inclusions and dystrophic neurites in brain. Science. 1997;277(5334):1990-3.

[10] Gomez-Tortosa E, MacDonald ME, Friend JC, Taylor SAM, Weiler LJ, Cupples LA, Srinidhi J, Gusella JF, Bird ED, Vonsattel JP, Myers RH. Quantitative neuropathological changes in presymptomatic Huntington's disease. Ann Neurol. 2001;49(1):29-34.

[11] Arrasate M, Mitra S, Schweitzer ES, Segal MR, Finkbeiner S. Inclusion body formation reduces levels of mutant huntingtin and the risk of neuronal death. Nature. 2004;431(7010):805-10.

[12] Tsvetkov AS, Arrasate M, Barmada S, Ando DM, Sharma P, Shaby BA, Finkbeiner S. Proteostasis of polyglutamine varies among neurons and predicts neurodegeneration. Nat Chem Biol. 2013;9(9):586-92.

[13] Besant PG, Tan E, Attwood PV. Mammalian protein histidine kinases. Int J Biochem Cell Biol. 2003;35(3):297-309.

[14] Manning G, Whyte DB, Martinez R, Hunter T, Sudarsanam $\mathrm{S}$. The protein kinase complement of the human genome. Science. 2002;298(5600):1912-34.

[15] Ginés S, Ivanova E, Seong I-S, Saura CA, MacDonald ME. Enhanced Akt signaling is an early pro-survival response that reflects $\mathrm{N}$-methyl-D-aspartate receptor activation in Huntington's disease knock-in striatal cells. J Biol Chem. 2003;278(50):50514-22.

[16] Ginés S, Paoletti P, Alberch J. Impaired TrkB-mediated ERK1/2 activation in huntington disease knock-in striatal cells involves reduced p52/p46 Shc expression. J Biol Chem. 2010;285(28):21537-48.

[17] Bjorkqvist M, Wild EJ, Thiele J, Silvestroni A, Andre R, Lahiri N, Raibon E, Lee R V, Benn CL, Soulet D, Magnusson A, Woodman B, Landles C, Pouladi MA, Hayden MR, Khalili-Shirazi A, Lowdell MW, Brundin P, Bates GP, Leavitt BR, Moller T, Tabrizi SJ. A novel pathogenic pathway of immune activation detectable before clinical onset in Huntington's disease. J Exp Med. 2008;205(8):1869-77. 
[18] Hsiao H-Y, Chen Y-C, Chen H-M, Tu P-H, Chern Y. A critical role of astrocyte-mediated nuclear factor- $\kappa \mathrm{B}$-dependent inflammation in Huntington's disease. Hum Mol Genet. 2013;22(9):1826-42.

[19] Mattson MP. Neuronal life-and-death signaling, apoptosis, and neurodegenerative disorders. Antioxid Redox Signal. 2006;8(11-12):1997-2006.

[20] Bowles KR, Brooks SP, Dunnett SB, Jones L. Gene expression and behaviour in mouse models of HD. Brain Res Bull. 2012;88(2-3):276-84.

[21] Crocker SF, Costain WJ, Robertson HA. DNA microarray analysis of striatal gene expression in symptomatic transgenic Huntington's mice (R6/2) reveals neuroinflammation and insulin associations. Brain Res. 2006;1088(1): 176-86.

[22] Crook ZR, Housman D. Huntington's disease: Can mice lead the way to treatment? Neuron. 2011;69(3):423-35

[23] Ross CA. Polyglutamine pathogenesis: Emergence of unifying mechanisms for Huntington's disease and related disorders. Neuron. 2002;35(5):819-22.

[24] Seredenina T, Luthi-Carter R. What have we learned from gene expression profiles in Huntington's disease? Neurobiol Dis. 2012;45(1):83-98.

[25] Zucker B, Luthi-Carter R, Kama J a, Dunah AW, Stern E a, Fox JH, Standaert DG, Young AB, Augood SJ. Transcriptional dysregulation in striatal projection- and interneurons in a mouse model of Huntington's disease: Neuronal selectivity and potential neuroprotective role of HAP1. Hum Mol Genet. 2005;14(2):179-89.

[26] Apostol BL, Illes K, Pallos J, Bodai L, Wu J, Strand A, Schweitzer ES, Olson JM, Kazantsev A, Marsh JL, Thompson LM. Mutant huntingtin alters MAPK signaling pathways in PC12 and striatal cells: ERK1/2 protects against mutant huntingtin-associated toxicity. Hum Mol Genet. 2006;15(2):273-85.

[27] Lin SY, Makino K, Xia W, Matin A, Wen Y, Kwong KY, Bourguignon L, Hung MC. Nuclear localization of EGF receptor and its potential new role as a transcription factor. Nat Cell Biol. 2001;3(9):802-8.

[28] Cabodi S, Morello V, Masi A, Cicchi R, Broggio C, Distefano P, Brunelli E, Silengo L, Pavone F, Arcangeli A, Turco E, Tarone G, Moro L, Defilippi P. Convergence of integrins and EGF receptor signaling via PI3K/Akt/FoxO pathway in early gene Egr-1 expression. J Cell Physiol. 2009;218(2):294-303.

[29] Kong P-J, Kil M-O, Lee H, Kim S-S, Johnson GVW, Chun W. Increased expression of Bim contributes to the potentiation of serum deprivation-induced apoptotic cell death in Huntington's disease knock-in striatal cell line. Neurol Res. 2009;31(1):77-83

[30] Ro Y-T, Jang B-K, Shin CY, Park EU, Kim CG, Yang S-I. Akt regulates the expression of MafK, synaptotagmin I, and syntenin-1, which play roles in neuronal function. J Biomed Sci. 2010;17:18.

[31] Roux PP, Blenis J. ERK and p38 MAPK-activated protein kinases: A family of protein kinases with diverse biological functions. Microbiol Mol Biol Rev. 2004;68(2):320-44.

[32] Miloso M, Scuteri A, Foudah D, Tredici G. MAPKs as mediators of cell fate determination: An approach to neurodegenerative diseases. Curr Med Chem. 2008;15(6):538-48.

[33] Roze E, Betuing S, Deyts C, Marcon E, Brami-Cherrier K, Pagès C, Humbert S, Mérienne K, Caboche J. Mitogen- and stress-activated protein kinase-1 deficiency is involved in expanded-huntingtin-induced transcriptional dysregulation and striatal death. FASEB J. 2008;22(4):1083-93.
[34] Xuan Nguyen T Le, Choi JW, Lee SB, Ye K, Woo S-D, Lee $\mathrm{K}-\mathrm{H}$, Ahn J-Y. Akt phosphorylation is essential for nuclear translocation and retention in NGF-stimulated PC12 cells. Biochem Biophys Res Commun. 2006;349(2):789-98.

[35] Gallo KA, Johnson GL. Mixed-lineage kinase control of JNK and p38 MAPK pathways. Nat Rev Mol Cell Biol. 2002;3(9):663-72.

[36] Cheng Q, Chen L, Li Z, Lane WS, Chen J. ATM activates p53 by regulating MDM2 oligomerization and E3 processivity. EMBO J. 2009;28(24):3857-67.

[37] Bodai L, Marsh JL. A novel target for Huntington's disease: ERK at the crossroads of signaling. Bio Essays. 2012;34(2):142-8.

[38] Ebisuya M, Kondoh K, Nishida E. The duration, magnitude and compartmentalization of ERK MAP kinase activity: Mechanisms for providing signaling specificity. J Cell Sci. 2005;118(Pt 14):2997-3002.

[39] Kim J-Y, Kim Y-J, Lee S, Park J-H. The critical role of ERK in death resistance and invasiveness of hypoxia-selected glioblastoma cells. BMC Cancer. 2009;9:27.

[40] Roskoski R. MEK1/2 dual-specificity protein kinases: Structure and regulation. Biochem Biophys Res Commun. 2012;417(1):5-10.

[41] Hetman M, Gozdz A. Role of extracellular signal regulated kinases 1 and 2 in neuronal survival. Eur J Biochem. 2004;271(11):2050-5.

[42] Singer CA, Figueroa-Masot XA, Batchelor RH, Dorsa DM. The mitogen-activated protein kinase pathway mediates estrogen neuroprotection after glutamate toxicity in primary cortical neurons. J Neurosci. 1999;19(7):2455-63.

[43] Anglada-Huguet M, Giralt A, Perez-Navarro E, Alberch J, Xifró X. Activation of Elk-1 participates as a neuroprotective compensatory mechanism in models of Huntington's disease. J Neurochem. 2012;121(4):639-48.

[44] Biswas SC, Greene LA. Nerve growth factor (NGF) downregulates the $\mathrm{Bcl}-2$ homology 3 ( $\mathrm{BH} 3$ ) domain-only protein Bim and suppresses its proapoptotic activity by phosphorylation. J Biol Chem. 2002;277(51):49511-6.

[45] Ley R, Ewings KE, Hadfield K, Howes E, Balmanno K, Cook SJ. Extracellular signal-regulated kinases $1 / 2$ are serum-stimulated "Bim(EL) kinases" that bind to the BH3only protein $\mathrm{Bim}(\mathrm{EL})$ causing its phosphorylation and turnover. J Biol Chem. 2004;279(10):8837-47.

[46] Cowley S, Paterson H, Kemp P, Marshall CJ. Activation of MAP kinase kinase is necessary and sufficient for PC12 differentiation and for transformation of NIH $3 \mathrm{~T} 3$ cells. Cell. 1994;77(6):841-52

[47] Pang L, Zheng CF, Guan KL, Saltiel AR. Nerve growthfactor stimulates a novel protein-kinase in PC-12 cells that phosphorylates and activates mitogen-activated proteinkinase kinase (MEK). Biochem J. 1995;307(2):513-9.

[48] Segal RA, Greenberg ME. Intracellular signaling pathways activated by neurotrophic factors. Annu Rev Neurosci. 1996;19:463-89.

[49] Li X, Newbern JM, Wu Y, Morgan-Smith M, Zhong J, Charron J, Snider WD. MEK is a key regulator of gliogenesis in the developing brain. Neuron. 2012;75(6):1035-50.

[50] Gokce O, Runne H, Kuhn A, Luthi-Carter R. Short-term striatal gene expression responses to brain-derived neurotrophic factor are dependent on MEK and ERK activation. PLoS One. 2009;4(4):e5292.

[51] Liebelt B, Papapetrou P, Ali A, Guo M, Ji X, Peng C, Rogers R, Curry A, Jimenez D, Ding Y. Exercise preconditioning reduces neuronal apoptosis in stroke by up-regulating heat shock protein-70 (heat shock 
protein-72) and extracellular-signal-regulated-kinase 1/2. Neuroscience. 2010;166(4):1091-100.

[52] Yu C-G, Yezierski RP, Joshi A, Raza K, Li Y, Geddes JW. Involvement of ERK2 in traumatic spinal cord injury. J Neurochem. 2010;113(1):131-42.

[53] Colucci-D'Amato L, Perrone-Capano C, di Porzio U. Chronic activation of ERK and neurodegenerative diseases. BioEssays. 2003;25(11):1085-95.

[54] Stanciu M. Persistent activation of ERK contributes to glutamate-induced oxidative toxicity in a neuronal cell line and primary cortical neuron cultures. J Biol Chem. 2000;275(16):12200-6.

[55] Zhu J-H, Kulich SM, Oury TD, Chu CT. Cytoplasmic aggregates of phosphorylated extracellular signal-regulated protein kinases in Lewy body diseases. Am J Pathol. 2002;161(6):2087-98.

[56] Dineley KT, Westerman M, Bui D, Bell K, Ashe KH, Sweatt JD. Beta-amyloid activates the mitogen-activated protein kinase cascade via hippocampal alpha7 nicotinic acetylcholine receptors: in vitro and in vivo mechanisms related to Alzheimer's disease. J Neurosci. 2001;21(12):4125-33.

[57] Chu CT, Levinthal DJ, Kulich SM, Chalovich EM, DeFranco DB. Oxidative neuronal injury. The dark side of ERK1/2. Eur J Biochem. 2004;271(11):2060-6.

[58] Fusco FR, Anzilotti S, Giampá C, Dato C, Laurenti D, Leuti A, Colucci D'Amato L, Perrone L, Bernardi G, Melone $\mathrm{MAB}$. Changes in the expression of extracellular regulated kinase (ERK 1/2) in the R6/2 mouse model of Huntington's disease after phosphodiesterase IV inhibition. Neurobiol Dis. 2012;46(1):225-33.

[59] Saavedra A, Giralt A, Rué L, Xifró X, Xu J, Ortega Z, Lucas JJ, Lombroso PJ, Alberch J, Pérez-Navarro E. Striatal-enriched protein tyrosine phosphatase expression and activity in Huntington's disease: A STEP in the resistance to excitotoxicity. J Neurosci. 2011;31(22):8150-62.

[60] Luo S, Vacher C, Davies JE, Rubinsztein DC. Cdk5 phosphorylation of huntingtin reduces its cleavage by caspases: Implications for mutant huntingtin toxicity. J Cell Biol. 2005;169(4):647-56

[61] Graham RK, Deng Y, Slow EJ, Haigh B, Bissada N, Lu G, Pearson J, Shehadeh J, Bertram L, Murphy Z, Warby SC, Doty CN, Roy S, Wellington CL, Leavitt BR, Raymond LA, Nicholson DW, Hayden MR. Cleavage at the caspase-6 site is required for neuronal dysfunction and degeneration due to mutant huntingtin. Cell. 2006;125(6):1179-91.

[62] Warby SC, Doty CN, Graham RK, Shively J, Singaraja RR, Hayden MR. Phosphorylation of huntingtin reduces the accumulation of its nuclear fragments. Mol Cell Neurosci. 2009;40(2):121-7.

[63] Liévens J-C, Rival T, Iché M, Chneiweiss H, Birman S. Expanded polyglutamine peptides disrupt EGF receptor signaling and glutamate transporter expression in Drosophila. Hum Mol Genet. 2005;14(5):713-24.

[64] Mazarakis NK, Cybulska-Klosowicz A, Grote H, Pang T, Van Dellen A, Kossut M, Blakemore C, Hannan AJ. Deficits in experience-dependent cortical plasticity and sensorydiscrimination learning in presymptomatic Huntington's disease mice. J Neurosci. 2005;25(12):3059-66.

[65] Cowin R-M, Bui N, Graham D, Green JR, Grueninger S, Yuva-Paylor L a, Syed AU, Weiss A, Paylor R. Onset and progression of behavioral and molecular phenotypes in a novel congenic R6/2 line exhibiting intergenerational CAG repeat stability. PLoS One. 2011;6(12):e28409.

[66] Lione LA, Carter RJ, Hunt MJ, Bates GP, Morton AJ, Dunnett SB. Selective discrimination learning impairments in mice expressing the human Huntington's disease mutation. J Neurosci. 1999;19(23):10428-37.

[67] Cayzac S, Delcasso S, Paz V, Jeantet Y, Cho YH. Changes in striatal procedural memory coding correlate with learning deficits in a mouse model of Huntington disease. Proc Natl Acad Sci U S A. 2011;108(22):9280-5.

[68] Brooks SP, Janghra N, Workman VL, Bayram-Weston Z, Jones L, Dunnett SB. Longitudinal analysis of the behavioural phenotype in R6/1 (C57BL/6J) Huntington's disease transgenic mice. Brain Res Bull. 2012;88(2-3):94103.

[69] Liot G, Zala D, Pla P, Mottet G, Piel M, Saudou F. Mutant Huntingtin alters retrograde transport of TrkB receptors in striatal dendrites. J Neurosci. 2013;33(15):6298-309.

[70] Baksi S, Jana NR, Bhattacharyya NP, Mukhopadhyay D. Grb2 is regulated by foxd3 and has roles in preventing accumulation and aggregation of mutant huntingtin. PLoS One. 2013;8(10):e76792.

[71] Giralt A, Rodrigo T, Martín ED, Gonzalez JR, Milá M, Ceña V, Dierssen M, Canals JM, Alberch J. Brain-derived neurotrophic factor modulates the severity of cognitive alterations induced by mutant huntingtin: Involvement of phospholipaseCgamma activity and glutamate receptor expression. Neuroscience. 2009;158(4):1234-50.

[72] Lievens J. Abnormal phosphorylation of synapsin I predicts a neuronal transmission impairment in the R6/2 Huntington's disease transgenic mice. Mol Cell Neurosci. 2002;20(4):638-48.

[73] Gianfriddo M, Melani A, Turchi D, Giovannini MG, Pedata F. Adenosine and glutamate extracellular concentrations and mitogen-activated protein kinases in the striatum of Huntington transgenic mice. Selective antagonism of adenosine A2A receptors reduces transmitter outflow. Neurobiol Dis. 2004;17(1):77-88

[74] Gauthier LR, Charrin BC, Borrell-Pages M, Dompierre JP, Rangone H, Cordelieres FP, De Mey J, MacDonald ME, Lessmann V, Humbert S, Saudou F. Huntingtin controls neurotrophic support and survival of neurons by enhancing BDNF vesicular transport along microtubules. Cell. 2004;118(1):127-38.

[75] Baquet ZC, Gorski JA, Jones KR. Early striatal dendrite deficits followed by neuron loss with advanced age in the absence of anterograde cortical brain-derived neurotrophic factor. J Neurosci. 2004;24(17):4250-8.

[76] Zuccato C, Cattaneo E. Role of brain-derived neurotrophic factor in Huntington's disease. Prog Neurobiol. 2007;81(56):294-330

[77] Iijima-ando K, Wu P, Drier EA, Iijima K, Yin JCP. cAMPresponse element-binding protein and heat-shock protein 70 additively suppress polyglutamine-mediated toxicity in Drosophila. Proc Natl Acad Sci U S A. 2005;102(29):102616.

[78] Liévens J-C, Iché M, Laval M, Faivre-Sarrailh C, Birman S. AKT-sensitive or insensitive pathways of toxicity in glial cells and neurons in Drosophila models of Huntington's disease. Hum Mol Genet. 2008;17(6):882-94

[79] Maher P, Dargusch R, Bodai L, Gerard PE, Purcell JM, Marsh JL. ERK activation by the polyphenols fisetin and resveratrol provides neuroprotection in multiple models of Huntington's disease. Hum Mol Genet. 2011;20(2): 261-70.

[80] Scotter EL, Goodfellow CE, Graham ES, Dragunow M, Glass M. Neuroprotective potential of $\mathrm{CB} 1$ receptor agonists in an in vitro model of Huntington's disease. Br J Pharmacol. 2010;160(3):747-61. 
[81] Zhang JH, Zhang DS, McQuade JS, Behbehani M, Tsien JZ, Xu M. C-fos regulates neuronal excitability and survival. Nat Genet. 2002;30(4):416-20.

[82] Vanhoutte P, Barnier J, Guibert B, Pagès C, Besson M, Hipskind RA, Page C, Caboche J. Glutamate induces phosphorylation of Elk-1 and CREB, along with c-fos activation, via an extracellular pathway in brain slices glutamate induces phosphorylation of Elk-1 and CREB, along with c -fos activation, via an extracellular signal-regulated $\mathrm{Ki}$. Mol Cell Biol. 1999;19(1):136-46.

[83] Deak M, Clifton AD, Lucocq LM, Alessi DR. Mitogenand stress-activated protein kinase-1 (MSK1) is directly activated by MAPK and SAPK2/p38, and may mediate activation of CREB. EMBO J. 1998;17(15):4426-41.

[84] Soloaga A, Thomson S, Wiggin GR, Rampersaud N, Dyson MH, Hazzalin C a, Mahadevan LC, Arthur JSC. MSK2 and MSK1 mediate the mitogen- and stress-induced phosphorylation of histone H3 and HMG-14. EMBO J. 2003;22(11):2788-97.

[85] Song C, Perides G, Liu YF. Expression of full-length polyglutamine-expanded Huntingtin disrupts growth factor receptor signaling in rat pheochromocytoma (PC12) cells. J Biol Chem. 2002;277(8):6703-7.

[86] Colin E, Régulier E, Perrin V, Dürr A, Brice A, Aebischer P, Déglon N, Humbert S, Saudou F. Akt is altered in an animal model of Huntington's disease and in patients. Eur J Neurosci. 2005;21(6):1478-88.

[87] Liu YF, Deth RC, Devys D. SH3 domain-dependent association of Huntingtin with epidermal growth factor receptor signaling complexes. J Biol Chem. 1997;272(13):8121-4.

[88] Humbert S. Huntingtin phosphorylation and signaling pathways that regulate toxicity in Huntington's disease. Clin Neurosci Res. 2003;3(3):149-55.

[89] Miaczynska M, Pelkmans L, Zerial M. Not just a sink: Endosomes in control of signal transduction. Curr Opin Cell Biol. 2004;16(4):400-6.

[90] Melone MAB, Calarco A, Petillo O, Margarucci S, ColucciD'Amato L, Galderisi U, Koverech G, Peluso G. Mutant huntingtin regulates EGF receptor fate in non-neuronal cells lacking wild-type protein. Biochim Biophys Acta. 2013;1832(1):105-13

[91] Brito V, Puigdellivol M, Giralt A, del Toro D, Alberch JBS Imbalance of p75 NTR/TrkB protein expression in Huntington's disease: Implication for neuroprotective therapies. Cell Death Dis. 2013;4(e595):1-15.

[92] Ginés S, Bosch M, Marco S, Gavaldá N, Díaz-Hernández M, Lucas JJ, Canals JM, Alberch J. Reduced expression of the TrkB receptor in Huntington's disease mouse models and in human brain. Eur J Neurosci. 2006;23(3):649-58.

[93] Choi Y, Lin SL, Lee B, Kurup P, Cho H, Janice R, Lombroso PJ, Obrietan K. Status epilepticus-induced somatostatinergic hilar interneuron degeneration is regulated by striatal enriched protein tyrosine phosphatase. J Neurosci. 2007;27(11):2999-3009.

[94] Wang P, Li B, Zhou L, Fei E, Wang G. The KDEL receptor induces autophagy to promote the clearance of neurodegenerative disease-related proteins. Neuroscience. 2011;190:43-55.

[95] Gu X, Greiner ER, Mishra R, Kodali R, Osmand A, Finkbeiner S, Steffan JS, Thompson LM, Wetzel R, Yang XW. Serines 13 and 16 are critical determinants of full-length human mutant huntingtin induced disease pathogenesis in HD mice. Neuron. 2009;64(6):828-40.

[96] Thompson LM, Aiken CT, Kaltenbach LS, Agrawal N, Illes K, Khoshnan A, Martinez-Vincente M, Arrasate M,
O’Rourke JG, Khashwji H, Lukacsovich T, Zhu Y-Z, Lau AL, Massey A, Hayden MR, Zeitlin SO, Finkbeiner S, Green KN, LaFerla FM, Bates G, Huang L, Patterson PH, Lo DC, Cuervo AM, Marsh JL, Steffan JS. IKK phosphorylates Huntingtin and targets it for degradation by the proteasome and lysosome. J Cell Biol. 2009;187(7):1083-99.

[97] Atwal RS, Desmond CR, Caron N, Maiuri T, Xia J, Sipione S, Truant R. Kinase inhibitors modulate huntingtin cell localization and toxicity. Nat Chem Biol. 2011;7(7):453-60.

[98] Havel LS, Wang C-E, Wade B, Huang B, Li S, Li X-J. Preferential accumulation of $\mathrm{N}$-terminal mutant huntingtin in the nuclei of striatal neurons is regulated by phosphorylation. Hum Mol Genet. 2011;20(7):1424-37.

[99] Atwal RS, Xia J, Pinchev D, Taylor J, Epand RM, Truant R. Huntingtin has a membrane association signal that can modulate huntingtin aggregation, nuclear entry and toxicity. Hum Mol Genet. 2007;16(21):2600-15.

[100] Desmond CR, Maiuri T, Truant R. A multifunctional, multipathway intracellular localization signal in Huntingtin. Commun Integr Biol. 2013;6(2):e23318.

[101] Khoshnan A, Patterson PH. The role of $\mathrm{I} \kappa \mathrm{B}$ kinase complex in the neurobiology of Huntington's disease. Neurobiol Dis. 2011;43(2):305-11.

[102] Bauer PO, Nukina N. The pathogenic mechanisms of polyglutamine diseases and current therapeutic strategies. J Neurochem. 2009;110(6):1737-65.

[103] Maiuri T, Woloshansky T, Xia J, Truant R. The huntingtin N17 domain is a multifunctional CRM1 and Ran-dependent nuclear and cilial export signal. Hum Mol Genet. 2013;22(7):1383-94.

[104] Zala D, Colin E, Rangone H, Liot G, Humbert S, Saudou F. Phosphorylation of mutant huntingtin at S421 restores anterograde and retrograde transport in neurons. Hum Mol Genet. 2008;17(24):3837-46.

[105] Schilling B, Gafni J, Torcassi C, Cong X, Row RH, LaFevreBernt M a, Cusack MP, Ratovitski T, Hirschhorn R, Ross Ca, Gibson BW, Ellerby LM. Huntingtin phosphorylation sites mapped by mass spectrometry. Modulation of cleavage and toxicity. J Biol Chem. 2006;281(33):23686-97.

[106] Su SC, Tsai L-H. Cyclin-dependent kinases in brain development and disease. Annu Rev Cell Dev Biol. 2011;27:465-91.

[107] Tsai LH, Takahashi T, Caviness VS, Harlow E. Activity and expression pattern of cyclin-dependent kinase 5 in the embryonic mouse nervous system. Development. 1993;119(4):1029-40.

[108] Harada T, Morooka T, Ogawa S, Nishida E. ERK induces p35, a neuron-specific activator of Cdk5, through induction of Egr1. Nat Cell Biol. 2001;3(5):453-9.

[109] Tokuoka H, Saito T, Yorifuji H, Wei F, Kishimoto T, Hisanaga S. Brain-derived neurotrophic factor-induced phosphorylation of neurofilament-H subunit in primary cultures of embryo rat cortical neurons. J Cell Sci. 2000;113 Pt 6:1059-68.

[110] Bogush A, Pedrini S, Pelta-Heller J, Chan T, Yang Q, Mao Z, Sluzas E, Gieringer T, Ehrlich ME. AKT and CDK5/p35 mediate brain-derived neurotrophic factor induction of DARPP-32 in medium size spiny neurons in vitro. J Biol Chem. 2007;282(10):7352-9.

[111] Modi PK, Komaravelli N, Singh N, Sharma P. Interplay between MEK-ERK signaling, cyclin D1, and cyclindependent kinase 5 regulates cell cycle reentry and apoptosis of neurons. Mol Biol Cell. 2012;23(18):3722-30.

[112] Sharma P, Veeranna, Sharma M, Amin ND, Sihag RK, Grant P, Ahn N, Kulkarni AB, Pant HC. Phosphorylation of MEK1 
by cdk $5 / \mathrm{p} 35$ down-regulates the mitogen-activated protein kinase pathway. J Biol Chem. 2002;277(1):528-34.

[113] Zheng Y, Li B, Kanungo J, Kesavapany S, Amin N, Grant $\mathrm{P}$, Pant HC. Cdk5 modulation of mitogen-activated protein kinase signaling regulates neuronal survival. Mol Biol Cell. 2007; 18:404-13.

[114] Li B-S, Zhang L, Takahashi S, Ma W, Jaffe H, Kulkarni AB, Pant HC. Cyclin-dependent kinase 5 prevents neuronal apoptosis by negative regulation of c-Jun $\mathrm{N}$-terminal kinase 3. EMBO J. 2002;21(3):324-33.

[115] Li B-S, Ma W, Jaffe H, Zheng Y, Takahashi S, Zhang L, Kulkarni AB, Pant HC. Cyclin-dependent kinase-5 is involved in neuregulin-dependent activation of phosphatidylinositol 3-kinase and Akt activity mediating neuronal survival. J Biol Chem. 2003;278(37):35702-9.

[116] Cheung ZH, Ip NY. Cdk5: Mediator of neuronal death and survival. Neurosci Lett. 2004;361(1-3):47-51.

[117] Dhavan R, Tsai LH. A decade of CDK5. Nat Rev Mol Cell Biol. 2001;2(10):749-59.

[118] Patrick GN, Zukerberg L, Nikolic M, de la Monte S, Dikkes P, Tsai LH. Conversion of p35 to p25 deregulates Cdk5 activity and promotes neurodegeneration. Nature. 1999;402(6762):615-22.

[119] Cheung ZH, Ip NY. Cdk5: A multifaceted kinase in neurodegenerative diseases. Trends Cell Biol. 2012;22(3):169-75.

[120] Lu T, Pan Y, Kao S, Li C, Kohane I. Gene regulation and DNA damage in the ageing human brain. Nature. 2004:429:883-91.

[121] Anne SL, Saudou F, Humbert S. Phosphorylation of huntingtin by cyclin-dependent kinase 5 is induced by DNA damage and regulates wild-type and mutant huntingtin toxicity in neurons. J Neurosci. 2007;27(27):7318-28.

[122] Paoletti P, Vila I, Rifé M, Lizcano JM, Alberch J, Ginés S. Dopaminergic and glutamatergic signaling crosstalk in Huntington's disease neurodegeneration: The role of p25/cyclin-dependent kinase 5. J Neurosci. 2008;28(40): 10090-101.

[123] Muchowski PJ, Ning K, D’Souza-Schorey C, Fields S. Requirement of an intact microtubule cytoskeleton for aggregation and inclusion body formation by a mutant huntingtin fragment. Proc Natl Acad Sci U S A. 2002;99(2): 727-32.

[124] Taylor JP. Aggresomes protect cells by enhancing the degradation of toxic polyglutamine-containing protein. Hum Mol Genet. 2003;12(7):749-57.

[125] Webb JL, Ravikumar B, Rubinsztein DC. Microtubule disruption inhibits autophagosome-lysosome fusion: Implications for studying the roles of aggresomes in polyglutamine diseases. Int J Biochem Cell Biol. 2004;36(12):2541-50.

[126] Kaminosono S, Saito T, Oyama F, Ohshima T, Asada A, Nagai Y, Nukina N, Hisanaga S-I. Suppression of mutant Huntingtin aggregate formation by $\mathrm{Cdk} 5 / \mathrm{p} 35$ through the effect on microtubule stability. J Neurosci. 2008;28(35):8747-55.

[127] Niethammer M, Smith DS, Ayala R, Peng J, Ko J, Lee MS, Morabito M, Tsai LH. NUDEL is a novel Cdk5 substrate that associates with LIS1 and cytoplasmic dynein. Neuron. 2000;28(3):697-711.

[128] Owada Y, Utsunomiya A, Yoshimoto T, Kondo H. Expression of mRNA for Akt, serine-threonine protein kinase, in the brain during development and its transient enhancement following axotomy of hypoglossal nerve. J Mol Neurosci. 1997;9(1):27-33.

[129] Noshita N, Lewen A, Sugawara T, Chan PH. Evidence of phosphorylation of Akt and neuronal survival after transient focal cerebral ischemia in mice. J Cerebreal Blood Flow Metab. 2001;21(12):1442-50.

[130] Endo H, Nito C, Kamada H, Nishi T, Chan PH. Activation of the Akt/GSK3beta signaling pathway mediates survival of vulnerable hippocampal neurons after transient global cerebral ischemia in rats. J Cereb Blood Flow Metab. 2006;26(12):1479-89.

[131] Zhang Y, Leavitt BR, van Raamsdonk JM, Dragatsis I, Goldowitz D, MacDonald ME, Hayden MR, Friedlander RM. Huntingtin inhibits caspase-3 activation. EMBO J. 2006;25(24):5896-906.

[132] Hashimoto M, Bar-On P, Ho G, Takenouchi T, Rockenstein E, Crews L, Masliah E. Beta-synuclein regulates Akt activity in neuronal cells. A possible mechanism for neuroprotection in Parkinson's disease. J Biol Chem. 2004;279(22):23622-9.

[133] Burgering BMT, Kops GJPL. Cell cycle and death control: Long live Forkheads. Trends Biochem Sci. 2002;27(7):35260.

[134] Meng F, Liu L, Chin PC, D'Mello SR. Akt is a downstream target of NF-kappa B. J Biol Chem. 2002;277(33):29674-80.

[135] Brunet A, Bonni A, Zigmond MJ, Lin MZ, Juo P, Hu LS, Anderson MJ, Arden KC, Blenis J, Greenberg ME. Akt promotes cell survival by phosphorylating and inhibiting a forkhead transcription factor university of california at san diego. Cell. 1999;96:857-68.

[136] Tang ED, Nunez G, Barr FG, Guan K-L. Negative regulation of the forkhead transcription factor FKHR by Akt. J Biol Chem. 1999;274(24):16741-6.

[137] Humbert S, Bryson EA, Cordelie FP, Connors NC, Datta SR, Finkbeiner S, Greenberg ME, Saudou F. The IGF1/Akt Pathway is neuroprotective in Huntington's disease and involves huntingtin phosphorylation by Akt. Dev Cell. 2002;2(6):831-7.

[138] Bardai FH, D'Mello SR. Selective toxicity by HDAC3 in neurons: Regulation by Akt and GSK3beta. J Neurosci. 2011;31(5):1746-51.

[139] Junyent F, de Lemos L, Verdaguer E, Pallàs M, Folch J, BeasZárate C, Camins A, Auladell C. Lack of Jun-N-terminal kinase 3 (JNK3) does not protect against neurodegeneration induced by 3-nitropropionic acid. Neuropathol Appl Neurobiol. 2012;38(4):311-21.

[140] Chong ZZ, Li F, Maiese K. Activating Akt and the brain's resources to drive cellular survival and prevent inflammatory injury. Histol Histopathol. 2005;20(1):299-315.

[141] Song G, Ouyang G, Bao S. The activation of Akt/PKB signaling pathway and cell survival. J Cell Mol Med. 2005;9(1):59-71.

[142] Bayascas JR, Alessi DR. Regulation of Akt/PKB Ser473 phosphorylation. Mol Cell. 2005;18(2):143-5.

[143] Gao T, Furnari F, Newton AC. PHLPP: A phosphatase that directly dephosphorylates Akt, promotes apoptosis, and suppresses tumor growth. Mol Cell. 2005;18(1):13-24.

[144] Chen WS, Xu P, Gottlob K, Chen M, Sokol K, Shiyanova T, Roninson I, Weng W, Suzuki R, Tobe K, Kadowaki T, Hay N. Growth retardation and increased apoptosis in mice with homozygous disruption of the akt1 gene. Genes Dev. 2001;15(312):2203-8.

[145] Cho H, Mu J, Kim JK, Thorvaldsen JL, Chu Q, Crenshaw EB, Kaestner KH, Bartolomei MS, Shulman GI, Birnbaum MJ. Insulin resistance and a diabetes mellitus-like syndrome in mice lacking the protein kinase Akt2 (PKB beta). Science. 2001;292(5522):1728-31.

[146] Warby SC, Chan EY, Metzler M, Gan L, Singaraja RR, Crocker SF, Robertson HA, Hayden MR. Huntingtin phosphorylation on serine 421 is significantly reduced in the 
striatum and by polyglutamine expansion in vivo. Hum Mol Genet. 2005;14(11):1569-77.

[147] Ritch JJ, Valencia A, Alexander J, Sapp E, Gatune L, Sangrey GR, Sinha S, Scherber CM, Zeitlin S, Sadri-Vakili G, Irimia D, DiFiglia M, Kegel KB. Multiple phenotypes in Huntington disease mouse neural stem cells. Mol Cell Neurosci. 2012;50(1):70-81

[148] Gharami K, Xie Y, An JJ, Tonegawa S, Xu B. Brainderived neurotrophic factor over-expression in the forebrain ameliorates Huntington's disease phenotypes in mice. J Neurochem. 2008;105(2):369-79.

[149] Saavedra A, García-Martínez JM, Xifró X, Giralt A, TorresPeraza JF, Canals JM, Díaz-Hernández M, Lucas JJ, Alberch J, Pérez-Navarro E. PH domain leucine-rich repeat protein phosphatase 1 contributes to maintain the activation of the PI3K/Akt pro-survival pathway in Huntington's disease striatum. Cell Death Differ. 2010;17(2):324-35.

[150] Ransome MI, Hannan AJ. Impaired basal and runninginduced hippocampal neurogenesis coincides with reduced Akt signaling in adult R6/1 HD mice. Mol Cell Neurosci. 2013;54:93-107.

[151] Simmons DA, Belichenko NP, Yang T, Condon C, Monbureau M, Shamloo M, Jing D, Massa SM, Longo FM. A small molecule TrkB ligand reduces motor impairment and neuropathology in R6/2 and BACHD mouse models of Huntington's disease. J Neurosci. 2013;33(48):18712-27.

[152] Xie Y, Hayden MR, Xu B. BDNF overexpression in the forebrain rescues Huntington's disease phenotypes in YAC128 mice. J Neurosci. 2010;30(44):14708-18.

[153] Colin E, Zala D, Liot G, Rangone H, Borrell-Pagès M, Li X-J, Saudou F, Humbert S. Huntingtin phosphorylation acts as a molecular switch for anterograde/retrograde transport in neurons. EMBO J. 2008;27(15):2124-34.

[154] Pineda JR, Pardo R, Zala D, Yu H, Humbert S, Saudou F. Genetic and pharmacological inhibition of calcineurin corrects the BDNF transport defect in Huntington's disease. Mol Brain. 2009;2(1):33.

[155] Pennuto M, Palazzolo I, Poletti A. Post-translational modifications of expanded polyglutamine proteins: Impact on neurotoxicity. Hum Mol Genet. 2009;18(R1):R40-7.

[156] Manning BD, Cantley LC. AKT/PKB signaling: Navigating downstream. Cell. 2007;129(7):1261-74.

[157] Varma H, Cheng R, Voisine C, Hart AC, Stockwell BR. Inhibitors of metabolism rescue cell death in Huntington's disease models. Proc Natl Acad Sci U S A. 2007;104(36):14525-30.

[158] Kang M, Choi S, Jeong S-J, Lee S-A, Kwak TK, Kim H, Jung O, Lee M-S, Ko Y, Ryu J, Choi Y-J, Jeong D, Lee HJ, Ye S-K, Kim S-H, Lee JW. Cross-talk between TGF $\beta 1$ and EGFR signalling pathways induces TM4SF5 expression and epithelial-mesenchymal transition. Biochem J. 2012; 443(3):691-700

[159] Song X, Thalacker FW, Nilsen-Hamilton M. Synergistic and multidimensional regulation Of plasminogen activator inhibitor type 1 expression by transforming growth factor Type $\beta$ and epidermal growth factor. J Biol Chem. 2012;287(15):12520-8

[160] Annunziata M, Granata R, Ghigo E. The IGF system. Acta Diabetol. 2011;48(1):1-9.

[161] Rong J, McGuire JR, Fang Z-H, Sheng G, Shin J-Y, Li S-H, Li X-J. Regulation of intracellular trafficking of huntingtinassociated protein-1 is critical for TrkA protein levels and neurite outgrowth. J Neurosci. 2006;26(22):6019-30.

[162] Conery AR, Cao Y, Thompson EA, Townsend CM, Ko TC, Luo K. Akt interacts directly with Smad3 to regulate the sensitivity to TGF-beta induced apoptosis. Nat Cell Biol. 2004;6(4):366-72.

[163] Remy I, Montmarquette A, Michnick SW. PKB/Akt modulates TGF-beta signalling through a direct interaction with Smad3. Nat Cell Biol. 2004;6(4):358-65.

[164] Massague J. Smad transcription factors. Genes Dev. 2005;19(23):2783-810.

[165] Song K, Cornelius SC, Reiss M, Danielpour D. Insulinlike growth factor-I inhibits transcriptional responses of transforming growth factor-beta by phosphatidylinositol 3-kinase/Akt-dependent suppression of the activation of Smad3 but not Smad2. J Biol Chem. 2003;278(40):3834251.

[166] Zuccato C, Marullo M, Conforti P, MacDonald ME, Tartari M, Cattaneo E. Systematic assessment of BDNF and its receptor levels in human cortices affected by Huntington's disease. Brain Pathol. 2008;18(2):225-38.

[167] Caja L, Sancho P, Bertran E, Fabregat I. Dissecting the effect of targeting the epidermal growth factor receptor on TGF- $\beta$ induced-apoptosis in human hepatocellular carcinoma cells. J Hepatol. 2011;55(2):351-8.

[168] Massague J. Integration of Smad and MAPK pathways: A link and a linker revisited. Genes Dev. 2003;17(24):2993-7.

[169] Jin X, Yin J, Kim S-H, Sohn Y-W, Beck S, Lim YC, Nam D-H, Choi Y-J, Kim H. EGFR-AKT-Smad signaling promotes formation of glioma stem-like cells and tumor angiogenesis by ID3-driven cytokine induction. Cancer Res. 2011;71(22):7125-34.

[170] Yamamura Y, Hua X, Bergelson S, Lodish HF. Critical role of Smads and AP-1 complex in transforming growth factorbeta -dependent apoptosis. J Biol Chem. 2000;275(46): 36295-302.

[171] Battaglia G, Cannella M, Riozzi B, Orobello S, MaatSchieman ML, Aronica E, Busceti CL, Ciarmiello A, Alberti S, Amico E, Sassone J, Sipione S, Bruno V, Frati L, Nicoletti F, Squitieri F. Early defect of transforming growth factor $\beta 1$ formation in Huntington's disease. J Cell Mol Med. 2011;15(3):555-71

[172] An MC, Zhang N, Scott G, Montoro D, Wittkop T, Mooney S, Melov S, Ellerby LM. Genetic correction of Huntington's disease phenotypes in induced pluripotent stem cells. Cell Stem Cell. 2012;253-63.

[173] Kandasamy M, Couillard-Despres S, Raber K a, Stephan M, Lehner B, Winner B, Kohl Z, Rivera FJ, Nguyen HP, Riess O, Bogdahn U, Winkler J, von Hörsten S, Aigner L. Stem cell quiescence in the hippocampal neurogenic niche is associated with elevated transforming growth factor-beta signaling in an animal model of Huntington disease. J Neuropathol Exp Neurol. 2010;69(7):717-28.

[174] Haddad JJ. N-methyl-D-aspartate (NMDA) and the regulation of mitogen-activated protein kinase (MAPK) signaling pathways: A revolving neurochemical axis for therapeutic intervention? Prog Neurobiol. 2005;77(4):252-82.

[175] Wang JQ, Fibuch EE, Mao L. Regulation of mitogenactivated protein kinases by glutamate receptors. J Neurochem. 2007;100(1):1-11.

[176] Keshet Y, Seger R. The MAP kinase signaling cascades: A system of hundreds of components regulates a diverse array of physiological functions. Methods in Molecular Biology. 2010;661:3-38

[177] Marshall CJ. Specificity of receptor tyrosine kinase signaling: Transient versus sustained extracellular signalregulated kinase activation. Cell. 1995;80(2):179-85.

[178] Weston CR, Davis RJ. The JNK signal transduction pathway. Curr Opin Genet Dev. 2002;12(1):14-21. 
[179] Kyriakis JM, Avruch J. Mammalian mitogen-activated protein kinase signal transduction pathways activated by stress and inflammation. Physiol Rev. 2001;81(2):807-69.

[180] Sherman MY, Goldberg AL. Cellular defenses against unfolded proteins: A cell biologist thinks about neurodegenerative diseases. Neuron. 2001;29(1):15-32.

[181] Tammariello S, Landreth G, Estus S. The role of Jun kinase in apoptosis. In: Mattson M, Estus S, Rangnekar V, editors. Role in Disease, Pathogenesis and Prevention. Elsevier Science; 2001, pp. 197-214.

[182] Dérijard B, Hibi M, Wu IH, Barrett T, Su B, Deng T, Karin M, Davis RJ. JNK1: A protein kinase stimulated by UV light and Ha-Ras that binds and phosphorylates the c-Jun activation domain. Cell. 1994;76(6):1025-37.

[183] Macián F, López-Rodríguez C, Rao A. Partners in transcription: NFAT and AP-1. Oncogene. 2001;20(19):2476-89.

[184] Putcha GV, Moulder KL, Golden JP, Bouillet P, Adams JA, Strasser A, Johnson EM. Induction of BIM, a proapoptotic BH3-only BCL-2 family member, is critical for neuronal apoptosis. Neuron. 2001;29(3):615-28.

[185] Whitfield J, Neame SJ, Paquet L, Bernard O, Ham J. Dominant-negative c-Jun promotes neuronal survival by reducing BIM expression and inhibiting mitochondrial cytochrome c release. Neuron. 2001;29(3):629-43.

[186] Morfini GA, You Y-M, Pollema SL, Kaminska A, Liu K, Yoshioka K, Björkblom B, Coffey ET, Bagnato C, Han D, Huang C-F, Banker G, Pigino G, Brady ST. Pathogenic huntingtin inhibits fast axonal transport by activating JNK3 and phosphorylating kinesin. Nat Neurosci. 2009;12(7): 864-71.

[187] Antoniou X, Falconi M, Di Marino D, Borsello T. JNK3 as a therapeutic target for neurodegenerative diseases. J Alzheimer's Dis. 2011;24(4):633-42.

[188] Resnick L, Fennell M. Targeting JNK3 for the treatment of neurodegenerative disorders. Drug Discov Today. 2004;9(21):932-9.

[189] De Lemos L, Junyent F, Verdaguer E, Folch J, Romero R, Pallás M, Ferrer I, Auladell C, Camins A. Differences in activation of ERK1/2 and p38 kinase in Jnk3 null mice following KA treatment. J Neurochem. 2010;114(5):1315-22.

[190] Yang DD, Kuan CY, Whitmarsh AJ, Rincón M, Zheng TS, Davis RJ, Rakic P, Flavell RA. Absence of excitotoxicityinduced apoptosis in the hippocampus of mice lacking the Jnk3 gene. Nature. 1997;389(6653):865-70.

[191] Junyent F, de Lemos L, Verdaguer E, Folch J, Ferrer I, Ortuño-Sahagún D, Beas-Zárate C, Romero R, Pallás M, Auladell C, Camins A. Gene expression profile in JNK3 null mice: A novel specific activation of the PI3K/AKT pathway. J Neurochem. 2011;117(2):244-52.

[192] Kim S, Han J, Lee SK, Koo M, Cho DH, Bae SY, Choi M-Y, Kim JS, Kim J-H, Choe J-H, Yang J-H, Nam SJ, Lee JE. Smad7 acts as a negative regulator of the epidermal growth factor (EGF) signaling pathway in breast cancer cells. Cancer Lett. 2012;314(2):147-54.

[193] Massagué J. TGF-beta signal transduction. Annu Rev Biochem. 1998;67:753-91.

[194] Engel ME, Mcdonnell MA, Law BK, Moses HL. Interdependent SMAD and JNK signaling in transforming growth factor- $\beta$-mediated transcription interdependent SMAD and JNK signaling in transforming growth factor mediated transcription. Cell Biol Metab. 1999;274(52):37413-20.

[195] Yue J, Mulder KM. Requirement of Ras/MAPK pathway activation by transforming growth factor beta for transforming growth factor beta 1 production in a Smad-dependent pathway. J Biol Chem. 2000;275(40):30765-73.
[196] Yu L, Hébert MC, Zhang YE. TGF-beta receptor-activated p38 MAP kinase mediates Smad-independent TGF-beta responses. EMBO J. 2002;21(14):3749-59.

[197] Chang K-H, de Pablo Y, Lee H, Lee H, Smith MA, Shah $\mathrm{K}$. Cdk5 is a major regulator of p38 cascade: Relevance to neurotoxicity in Alzheimer's disease. J Neurochem. 2010;113(5):1221-9.

[198] Sun K, Lee H, Smith MA, Shah K. Direct and indirect roles of cyclin-dependent kinase 5 as an upstream regulator in the c-Jun NH 2 -Terminal kinase cascade: Relevance to neurotoxic insults in Alzheimer's disease. Mol Biol Cell. 2009;20:4611-9.

[199] Jebelli JD, Hooper C, Garden GA, Pocock JM. Emerging roles of p53 in glial cell function in health and disease. Glia. 2012;60(4):515-25.

[200] Basu M, Bhattacharyya NP, Mohanty PK. Comparison of modules of wild type and mutant Huntingtin and TP53 protein interaction networks: Implications in biological processes and functions. PLoS One. 2013;8(5):e64838.

[201] Fan J, Gladding CM, Wang L, Zhang LYJ, Kaufman AM, Milnerwood AJ, Raymond LA. P38 MAPK is involved in enhanced NMDA receptor-dependent excitotoxicity in YAC transgenic mouse model of Huntington disease. Neurobiol Dis. 2012;45(3):999-1009.

[202] Wellington CL, Singaraja R, Ellerby L, Savill J, Roy S, Leavitt B, Cattaneo E, Hackam A, Sharp A, Thornberry N, Nicholson DW, Bredesen DE, Hayden MR. Inhibiting caspase cleavage of huntingtin reduces toxicity and aggregate formation in neuronal and nonneuronal cells. J Biol Chem. 2000;275(26):19831-8.

[203] Garcia M, Charvin D, Caboche J. Expanded huntingtin activates the c-Jun terminal kinase/c-Jun pathway prior to aggregate formation in striatal neurons in culture. Neuroscience. 2004;127(4):859-70.

[204] Liu YF. Expression of polyglutamine-expanded Huntingtin activates the SEK1-JNK pathway and induces apoptosis in a hippocampal neuronal cell line. J Biol Chem. 1998;273(44):28873-7.

[205] Liu YF, Dorow D, Marshall J. Activation of MLK2 mediated signaling cascades by polyglutamine-expanded huntingtin. J Biol Chem. 2000;275(25):19035-40.

[206] Meriin AB, Mabuchi K, Gabai VL, Yaglom JA, Kazantsev A, Sherman MY. Intracellular aggregation of polypeptides with expanded polyglutamine domain is stimulated by stress-activated kinase MEKK1. J Cell Biol. 2001;153(4):851-64.

[207] Perrin V, Dufour N, Raoul C, Hassig R, Brouillet E, Aebischer R, Luthi-Carter R, Deglon N. Implication of the JNK pathway in a rat model of Huntington's disease. Exp Neurol. 2009;215(1):191-200.

[208] Gotoh I, Adachi M, Nishida E. Identification and characterization of a novel MAP kinase kinase kinase, MLTK. J Biol Chem. 2001;276(6):4276-86.

[209] Gross EA, Callow MG, Waldbaum L, Thomas S, Ruggieri R. MRK, a mixed lineage kinase-related molecule that plays a role in gamma-radiation-induced cell cycle arrest. J Biol Chem. 2002;277(16):13873-82.

[210] Dorow DS, Devereux L, Tu GF, Price G, Nicholl JK, Sutherland GR, Simpson RJ. Complete nucleotide sequence, expression, and chromosomal localisation of human mixedlineage kinase 2. Eur J Biochem. 1995;234(2):492-500.

[211] Hirai S, Katoh M, Kyriakis JM, Zon LI, Rana A, Avruch J, Ohno S, Terada M. MST / MLK2, a Member of the mixed lineage kinase family, directly phosphorylates and activates SEK1, an MST / MLK2, a member of the mixed 
lineage kinase family, directly phosphorylates and activates SEK1, an activator of c-Jun N-terminal kinase. Enzymology. 1997;272(24):15167-73.

[212] Cuenda A, Dorow DS. Differential activation of stressactivated protein kinase kinases SKK4/MKK7 and SKK1/MKK4 by the mixed-lineage kinase- 2 and mitogenactivated protein kinase kinase (MKK) kinase-1. J Biochem. 1998;15:11-5.

[213] Hirai S-I. Differential activation of two JNK activators, MKK7 and SEK1, by MKN28-derived nonreceptor serine/threonine kinase/mixed lineage kinase 2. J Biol Chem. 1998;273(13):7406-12.

[214] Merritt SE, Mata M, Zhu C, Hu X, Holzman LB, Nihalani D. The mixed lineage kinase DLK utilizes MKK7 and not MKK4 as substrate the mixed lineage kinase DLK utilizes MKK7 and not MKK4 as substrate. Cell Biol Metab. 1999;274(15):10195-202.

[215] Nagata KI, Puls A, Futter C, Aspenstrom P, Schaefer E, Nakata T, Hirokawa N, Hall A. The MAP kinase kinase kinase MLK2 co-localizes with activated JNK along microtubules and associates with kinesin superfamily motor KIF3. EMBO J. 1998;17(1):149-58.

[216] Kouroku Y, Fujita E, Jimbo A, Kikuchi T, Yamagata T, Momoi MY, Kominami E, Kuida K, Sakamaki K, Yonehara S, Momoi T. Polyglutamine aggregates stimulate ER stress signals and caspase-12 activation. Hum Mol Genet. 2002;11(13):1505-15

[217] Nishitoh H, Matsuzawa A, Tobiume K, Saegusa K, Takeda $\mathrm{K}$, Inoue $\mathrm{K}$, Hori S, Kakizuka A, Ichijo H. ASK1 is essential for endoplasmic reticulum stress-induced neuronal cell death triggered by expanded polyglutamine repeats. Genes Dev. 2002;16(11):1345-55.

[218] Merienne K, Helmlinger D, Perkin GR, Devys D, Trottier Y. Polyglutamine expansion induces a protein-damaging stress connecting heat shock protein 70 to the JNK pathway. J Biol Chem. 2003;278(19):16957-67.

[219] Lim MJ, Lin T, Jakowlew SB. Signaling mechanisms of transforming growth factor- $\beta$ (TGF- $\beta$ ) in cancer: TGF- $\beta$ induces apoptosis in lung cells by a Smad-dependent mechanism. In: Cheng Y, editor. Tumor Suppressor Genes. InTech; 2005, pp. 145-80.

[220] Winograd-Katz SE, Levitzki A. Cisplatin induces PKB/Akt activation and p38(MAPK) phosphorylation of the EGF receptor. Oncogene. 2006;25(56):7381-90.

[221] Holmberg CI, Tran SEF, Eriksson JE, Sistonen L. Multisite phosphorylation provides sophisticated regulation of transcription factors. Trends Biochem Sci. 2002;27(12):619-27.

[222] Wang L, Ankati H, Akubathini SK, Balderamos M, Storey CA, Patel AV, Price V, Kretzschmar D, Bieh ER, D’Mello SR. Identification of novel 1,4-benzoxazine compounds that are protective in tissue culture and in vivo models of neurodegeneration. J Neurosci Res. 2010;88(9):1970-84.

[223] Taylor DM, Moser R, Régulier E, Breuillaud L, Dixon M, Beesen AA, Elliston L, Silva Santos MDF, Kim J, Jones L, Goldstein DR, Ferrante RJ, Luthi-Carter R. MAP kinase phosphatase 1 (MKP-1/DUSP1) is neuroprotective in Huntington's disease via additive effects of JNK and p38 inhibition. J Neurosci. 2013;33(6):2313-25.

[224] Yu Z, Li S, Evans J, Pillarisetti A, Li H, Li X. Mutant Huntingtin causes context-dependent neurodegeneration in mice with Huntington's disease. J Neurosci. 2003;23(6):2193202.

[225] Rattray I, Smith E, Gale R, Matsumoto K, Bates GP, Modo M. Correlations of behavioral deficits with brain pathology assessed through longitudinal MRI and histopathology in the R6/2 mouse model of HD. PLoS One. 2013;8(4): e60012.

[226] Mangiarini L, Sathasivam K, Seller M, Cozens B, Harper A, Hetherington C, Lawton M, Trottier Y, Lehrach H, Davies SW, Bates GP. Exon 1 of the HD gene with an expanded CAG repeat is sufficient to cause a progressive neurological phenotype in transgenic mice. Cell. 1996;87(3): 493-506.

[227] Rangone Á, Poizat G, Troncoso J, Ross CA, Macdonald $\mathrm{ME}$, Humbert S. The serum- and glucocorticoid-induced kinase SGK inhibits mutant huntingtin-induced toxicity by phosphorylating serine 421 of huntingtin. Eur J Neurosci. 2004;19:273-9.

[228] Patterson KI, Brummer T, Brien PMO, Daly RJ. Dualspecificity phosphatases: Critical regulators with diverse cellular targets. J Biochem. 2009;489:475-89.

[229] Luthi-Carter R, Hanson SA, Strand AD, Bergstrom DA, Chun W, Peters NL, Woods AM, Chan EY, Kooperberg C, Krainc D, Young AB, Tapscott SJ, Olson JM. Dysregulation of gene expression in the R6/2 model of polyglutamine disease: Parallel changes in muscle and brain. Hum Mol Genet. 2002;11(17):1911-26.

[230] Kuhn A, Goldstein DR, Hodges A, Strand AD, Sengstag T, Kooperberg C, Becanovic K, Pouladi M a, Sathasivam K, Cha J-HJ, Hannan AJ, Hayden MR, Leavitt BR, Dunnett SB, Ferrante RJ, Albin R, Shelbourne P, Delorenzi M, Augood SJ, Faull RLM, Olson JM, Bates GP, Jones L, Luthi-Carter R. Mutant huntingtin's effects on striatal gene expression in mice recapitulate changes observed in human Huntington's disease brain and do not differ with mutant huntingtin length or wild-type huntingtin dosage. Hum Mol Genet. 2007;16(15):1845-61.

[231] Jeannetau F, Deinhardt K, Miyoshi G, Bennett AM, Chao MV. The MAP kinase phosphatase, MKP-1, regulates BDNF-induced axon branching. Nat Neurosci. 2010;13(11):1373-9.

[232] Steffan JS, Bodai L, Pallos J, Poelman M, Mccampbell A, Apostol BL, Kazantsev A, Schmidt E, Zhu Y, Greenwald M, Kurokawa R, Housman DE, Jackson GR, Marsh JL, Thompson LM. Histone deacetylase inhibitors arrest neurodegeneration in Drosophila. Nature. 2001;413:739-43.

[233] Ferrante RJ, Kubilus JK, Lee J, Ryu H, Beesen A, Zucker B, Smith K, Kowall NW, Ratan RR, Luthi-carter R, Hersch SM. Histone deacetylase inhibition by sodium butyrate chemotherapy ameliorates the neurodegenerative phenotype in Huntington's disease mice. J Neurosci. 2003;23(28):9418-27.

[234] Vogelstein B, Lane D, Levine AJ. Surfing the p53 network. Nature. 2000;408(6810):307-10.

[235] Chang JR, Ghafouri M, Mukerjee R, Bagashev A, Chabrashvili T, Sawaya BE. Role of p53 in neurodegenerative diseases. Neurodegener Dis. 2012;9(2):68-80.

[236] Yaun J, Luo K, Zhang L, Cheville J, Lou Z. USP10 regulates p53 localization and stability by deubiquitinating p53. Cell. 2010;140(3):384-404.

[237] Zacchi P, Gostissa M, Uchida T, Salvagno C, Avolio F, Volinia S, Ronai Z, Blandino G, Schneider C, Del Sal G. The prolyl isomerase Pin1 reveals a mechanism to control p53 functions after genotoxic insults. Nature. 2002;419(6909):853-7.

[238] Zheng H, You H, Zhou XZ, Murray SA. The prolyl isomerase Pin 1 is a regulator of p53 in genotoxic response. Nature. 2002;419:849-54.

[239] Mantovani F, Tocco F, Girardini J, Smith P, Gasco M, Lu X, Crook T, Del Sal G. The prolyl isomerase Pin 1 orchestrates 
p53 acetylation and dissociation from the apoptosis inhibitor iASPP. Nat Struct Mol Biol. 2007;14(10):912-20.

[240] Grison A, Mantovani F, Comel A, Agostoni E, Gustincich S, Persichetti F, Del Sal G. Ser46 phosphorylation and prolyl-isomerase Pin1-mediated isomerization of p53 are key events in $\mathrm{p} 53$-dependent apoptosis induced by mutant huntingtin. Proc Natl Acad Sci U S A. 2011;108(44):1797984.

[241] Erickson JD, Bazan NG. The nucleolus fine-tunes the orchestration of an early neuroprotection response in neurodegeneration. Cell Death Differ. 2013;20(11):1435-7.

[242] Mayo LD, Donner DB. A phosphatidylinositol 3-kinase/Akt pathway promotes translocation of Mdm2 from the cytoplasm to the nucleus. Proc Natl Acad Sci U S A. 2001;98(20):11598-603.

[243] Zhou BP, Liao Y, Xia W, Zou Y, Spohn B, Hung M. HER2/neu induces P53 ubiquitination via Akt-mediated MDM2 phosphorylation. Nat Cell Biol. 2001;3:973-82.

[244] Jordan J, Galindo F, Prehn JHM, Weichselbaum RR, Beckett M, Ghadge GD, Roos RP, Leiden JM, Miller RJ. p53 expression induces apoptosis in hippocampal pyramidal neuron cultures. J Neurosci. 1997;17(4):1397-405.

[245] Morrison RS, Schwartzkroin PA, Jurgen H, Donehower A. Loss of the p53 tumor suppressor cell death gene protects neurons from kainate-induced cell death. J Neurosci. 1996;16(4):1337-45.

[246] Sipione S, Rigamonti D, Valenza M, Zuccato C, Conti L, Pritchard J, Kooperberg C, Olson JM, Cattaneo E. Early transcriptional profiles in huntingtin-inducible striatal cells by microarray analyses. Hum Mol Genet. 2002;11(17):195365

[247] Mayo LD, Seo YR, Jackson MW, Smith ML, Rivera Guzman J, Korgaonkar CK, Donner DB. Phosphorylation of human p53 at serine 46 determines promoter selection and whether apoptosis is attenuated or amplified. J Biol Chem. 2005;280(28):25953-9.

[248] Bae B-I, Xu H, Igarashi S, Fujimuro M, Agrawal N, Taya Y, Hayward SD, Moran TH, Montell C, Ross C a, Snyder SH, Sawa A. p53 mediates cellular dysfunction and behavioral abnormalities in Huntington's disease. Neuron. 2005;47(1):29-41.

[249] Guo X, Disatnik M, Monbureau M, Shamloo M, Mochlyrosen D, Qi X. Inhibition of mitochondrial fragmentation diminishes Huntington' $s$ disease - associated neurodegeneration. J Clin Invest. 2013;123(12):5371-88.

[250] Ghose J, Sinha M, Das E, Jana NR, Bhattacharyya NP. Regulation of miR-146a by RelA/NFkB and p53 in STHdh(Q111)/Hdh(Q111) cells, a cell model of Huntington's disease. PLoS One. 2011;6(8):e23837.

[251] Kreiner G, Bierhoff H, Armentano M, Rodriguez-Parkitna J, Sowodniok K, Naranjo JR, Bonfanti L, Liss B, Schütz G, Grummt I, Parlato R. A neuroprotective phase precedes striatal degeneration upon nucleolar stress. Cell Death Differ. 2013;20(11):1455-64.

[252] Steffan JS, Kazantsev A, Spasic-Boskovic O, Greenwald M, Zhu YZ, Gohler H, Wanker EE, Bates GP, Housman DE, Thompson LM. The Huntington's disease protein interacts with p53 and CREB-binding protein and represses transcription. Proc Natl Acad Sci U S A. 2000;97(12): 6763-8.

[253] Benn CL, Sun T, Sadri-Vakili G, McFarland KN, DiRocco DP, Yohrling GJ, Clark TW, Bouzou B, Cha J-HJ. Huntingtin modulates transcription, occupies gene promoters in vivo, and binds directly to DNA in a polyglutamine-dependent manner. J Neurosci. 2008;28(42):10720-33.
[254] Suhr ST, Senut MC, Whitelegge JP, Faull KF, Cuizon DB, Gage FH. Identities of sequestered proteins in aggregates from cells with induced polyglutamine expression. J Cell Biol. 2001;153(2):283-94.

[255] Feng Z, Jin S, Zupnick a, Hoh J, de Stanchina E, Lowe S, Prives C, Levine AJ. P53 tumor suppressor protein regulates the levels of huntingtin gene expression. Oncogene. 2006;25(1):1-7.

[256] Ryan AB, Zeitlin SO, Scrable H. Genetic interaction between expanded murine Hdh alleles and p53 reveal deleterious effects of $\mathrm{p} 53$ on Huntington's disease pathogenesis. Neurobiol Dis. 2006;24(2):419-27.

[257] Rubinsztein DC. The roles of intracellular proteindegradation pathways in neurodegeneration. Nature. 2006;443(7113):780-6.

[258] Glass CK, Saijo K, Winner B, Marchetto MC, Gage H. Mechanisms underlying inflammation in neurodegeneration. Cell. 2010;140(6):918-34.

[259] Träger U, Andre R, Lahiri N, Magnusson-Lind A, Weiss A, Grueninger S, McKinnon C, Sirinathsinghji E, Kahlon S, Pfister EL, Moser R, Hummerich H, Antoniou M, Bates GP, Luthi-Carter R, Lowdell MW, Björkqvist M, Ostroff GR, Aronin N, Tabrizi SJ. HTT-lowering reverses Huntington's disease immune dysfunction caused by $\mathrm{NF} \kappa \mathrm{B}$ pathway dysregulation. Brain. 2014;137(Pt 3):819-33.

[260] Franciosi S, Ryu JK, Shim Y, Hill A, Connolly C, Hayden MR, McLarnon JG, Leavitt BR. Age-dependent neurovascular abnormalities and altered microglial morphology in the YAC128 mouse model of Huntington disease. Neurobiol Dis. 2012;45(1):438-49.

[261] Karin M, Ben-neriah Y. Phosphorylation meets ubiquitination: The control of NF-kappaB activity. Annu Rev Immunol. 2000;18:621-63.

[262] Baldwin AS. The NF- $\kappa$ B and $\mathrm{I} \kappa \mathrm{B}$ proteins: New discoveries and insights. Annu Rev Immunol. 1996;14:649-81.

[263] Häcker H, Karin M. Regulation and function of IKK and IKK-related kinases. Sci STKE. 2006;357:re13.

[264] Kane LP, Shapiro VS, Stokoe D, Weiss A. Induction of NF$\mathrm{kB}$ by the AKT/PKB kinase. Curr Biol. 1999;9:601-4.

[265] Ozes ON, Mayo LD, Gustin J a, Pfeffer SR, Pfeffer LM, Donner DB. NF-kappaB activation by tumour necrosis factor requires the Akt serine-threonine kinase. Nature. 1999;401(6748):82-5.

[266] Romashkova JA, Makarov SS. NF-kappaB is a target of AKT in anti-apoptotic PDGF signalling. Nature. 1999;401(6748):86-90.

[267] Madrid LV, Wang CY, Guttridge DC, Schottelius AJ, Baldwin AS, Mayo MW. Akt suppresses apoptosis by stimulating the transactivation potential of the RelA/p65 subunit of NFkappaB. Mol Cell Biol. 2000;20(5):1626-38.

[268] Dan HC, Cooper MJ, Cogswell PC, Duncan JA, Ting JP, Baldwin AS. Akt-dependent regulation of NF- kB is controlled by mTOR and Raptor in association with IKK. Genes Dev. 2008;22:1490-500.

[269] Ghosh S, May MJ, Kopp EB. NF-kappa B and Rel proteins: Evolutionarily conserved mediators of immune responses. Annu Rev Immunol. 1998;16:225-60.

[270] Ghosh S, Karin M, Haven N. Missing pieces in the NF-kB puzzle. Cell. 2002;109:81-96.

[271] Khoshnan A, Ko J, Tescu S, Brundin P, Patterson PH. IKKalpha and IKKbeta regulation of DNA damage-induced cleavage of huntingtin. PLoS One. 2009;4(6):e5768.

[272] Mattson MP, Camandola S. NF- $\kappa$ B in neuronal plasticity and neurodegenerative disorders. $\mathrm{J}$ Clin Invest. 2001;107(3):247-54 
[273] Huang W-C, Ju T-K, Hung M-C, Chen C-C. Phosphorylation of CBP by IKK $\alpha$ promotes cell growth by switching the binding preference of CBP from p53 to NF- $\kappa \mathrm{B}$. Mol Cell. 2007;26(1):75-87.

[274] Chariot A. The NF-kappaB-independent functions of IKK subunits in immunity and cancer. Trends Cell Biol. 2009;19(8):404-13.

[275] Li Q, Lu Q, Bottero V, Estepa G, Morrison L, Mercurio F, Verma IM. Enhanced NF-kappaB activation and cellular function in macrophages lacking IkappaB kinase 1 (IKK1). Proc Natl Acad Sci U S A. 2005;102(35):12425-30.

[276] Lubin FD, Sweatt JD. The I $\kappa$ B kinase regulates chromatin structure during reconsolidation of conditioned fear memories. Neuron. 2008;55(6):942-57.

[277] Khoshnan A, Ko J, Watkin EE, Paige LA, Reinhart PH, Patterson PH. Activation of the IkB Kinase complex and nuclear Factor- kB contributes to mutant huntingtin neurotoxicity. J Neurosci. 2004;24(37):7999-8008.

[278] Ghosh A, Roy A, Liu X, Kordower JH, Mufson EJ, Hartley DM, Ghosh S, Mosley RL, Gendelman HE, Pahan K. Selective inhibition of NF-kappaB activation prevents dopaminergic neuronal loss in a mouse model of Parkinson's disease. Proc Natl Acad Sci U S A. 2007;104(47):18754-9.

[279] Zuccato C, Valenza M, Cattaneo E. Molecular mechanisms and potential therapeutical targets in Huntington's disease. Physiol Rev. 2010;90(3):905-81

[280] Landles C, Sathasivam K, Weiss A, Woodman B, Moffitt H, Finkbeiner S, Sun B, Gafni J, Ellerby LM, Trottier Y, Richards WG, Osmand A, Paganetti P, Bates GP. Proteolysis of mutant huntingtin produces an exon 1 fragment that accumulates as an aggregated protein in neuronal nuclei in Huntington disease. J Biol Chem. 2010;285(12):8808-23.

[281] Khoshnan A, Ko J, Patterson PH. Effects of intracellular expression of anti-huntingtin antibodies of various specificities on mutant huntingtin aggregation and toxicity. Proc Natl Acad Sci U S A. 2002;99(2):1002-7.

[282] Cho I-H, Hong J, Suh EC, Kim JH, Lee H, Lee JE, Lee S, Kim C-H, Kim DW, Jo E-K, Lee KE, Karin M, Lee SJ. Role of microglial IKKbeta in kainic acid-induced hippocampal neuronal cell death. Brain. 2008;131:3019-33.

[283] Jia H, Kast RJ, Steffan JS, Thomas EA. Selective histone deacetylase (HDAC) inhibition imparts beneficial effects in Huntington's disease mice: Implications for the ubiquitinproteasomal and autophagy systems. Hum Mol Genet. 2012;21(24):5280-93.

[284] Caron NS, Desmond CR, Xia J, Truant R. Polyglutamine domain flexibility mediates the proximity between flanking sequences in huntingtin. Proc Natl Acad Sci U S A. 2013;110(36):14610-5.

[285] Witt J, Barisic S, Schumann E, Allgöwer F, Sawodny O, Sauter T, Kulms D. Mechanism of PP2A-mediated IKK beta dephosphorylation: A systems biological approach. BMC Syst Biol. 2009;3:71.
[286] Metzler M, Gan L, Mazarei G, Graham RK, Liu L, Bissada N, Lu G, Leavitt BR, Hayden MR. Phosphorylation of Huntingtin at Ser421 in YAC128 neurons is associated with protection of YAC128 neurons from NMDA-mediated excitotoxicity and is modulated by PP1 and PP2A. J Neurosci. 2010;30(43):14318-29.

[287] Reijonen S, Kukkonen JP, Hyrskyluoto A, Kivinen J, Kairisalo M, Takei N, Lindholm D, Korhonen L. Downregulation of NF-kappaB signaling by mutant huntingtin proteins induces oxidative stress and cell death. Cell Mol Life Sci. 2010;67(11):1929-41.

[288] Hyrskyluoto A, Pulli I, Törnqvist K, Ho TH, Korhonen L, Lindholm D. Sigma-1 receptor agonist PRE084 is protective against mutant huntingtin-induced cell degeneration: Involvement of calpastatin and the NF- $\kappa \mathrm{B}$ pathway. Cell Death Dis. 2013;4:e646.

[289] Di Pardo A, Alberti S, Maglione V, Amico E, Cortes EP, Elifani F, Battaglia G, Busceti CL, Nicoletti F, Vonsattel JPG, Squitieri F. Changes of peripheral TGF- $\beta 1$ depend on monocytes-derived macrophages in Huntington disease. Mol Brain. 2013;6:55.

[290] Cao S, Zhang X, Edwards JP, Mosser DM. NF- $\kappa$ B1 (p50) homodimers differentially regulate pro- and antiinflammatory cytokines in macrophages. J Biol Chem. 2006;281(36):26041-50.

[291] Driessler F, Venstrom K, Sabat R, Asadullah K, Area B. Molecular mechanisms of interleukin-10-mediated inhibition of NF- k B activity: A role for p50. Clin Exp Immunol. 2004;135:64-73.

[292] Goswami A, Dikshit P, Mishra A, Mulherkar S, Nukina $\mathrm{N}$, Jana NR. Oxidative stress promotes mutant huntingtin aggregation and mutant huntingtin-dependent cell death by mimicking proteasomal malfunction. Biochem Biophys Res Commun. 2006;342(1):184-90.

[293] Godavarthi SK, Narender D, Mishra A, Goswami A, Rao SNR, Nukina N, Jana NR. Induction of chemokines, MCP1 , and $\mathrm{KC}$ in the mutant huntingtin expressing neuronal cells because of proteasomal dysfunction. J Neurochem. 2009;108(3):787-95.

[294] Subramaniam S, Unsicker K. ERK and cell death: ERK1/2 in neuronal death. FEBS J. 2010;277(1):22-9.

[295] Ji Y, Lu Y, Yang F, Shen W, Tang TT-T, Feng L, Duan S, Lu B. Acute and gradual increases in BDNF concentration elicit distinct signaling and functions in neurons. Nat Neurosci. 2010;13(3):302-9.

[296] Trettel F, Rigamonti D, Hilditch-Maguire P, Wheeler VC, Sharp AH, Persichetti F, Cattaneo E, MacDonald ME, Dominant phenotypes produced by the HD mutation in STHdh(Q111) striatal cells. Hum Mol Genet. 2000;9(19): 2799-809. 